\title{
COMPREENDENDO A INFLUÊNCIA DOS VALORES PESSOAIS NA PRONTIDÃO E NA INTENÇÃO DE USO DE TECNOLOGIAS
}

\section{UNDERSTANDING THE INFLUENCE OF PERSONAL VALUES ON READINESS AND INTENTION TO USE TECHNOLOGIES}

\section{DAIANE LINDNER RADONS}

Universidade Federal de Santa Maria

Doutoranda em Administração pela Universidade Federal de Santa Maria Orcid: http://orcid.org/0000-0003-3545-0741 / E-mail: daialindner@gmail.com Rua Padre Maximiliano, 1266, Bairro Santo Antônio, CEP 97900-000, Cerro Largo / RS

\section{CARLA ROSANE DA COSTA SCCOTT}

Universidade Federal de Santa Maria

Doutoranda em Extensão Rural pela Universidade Federal de Santa Maria

Orcid: http://orcid.org/0000-0002-4704-4209/E-mail: carlasccott@gmail.com

\section{VANIA DE FÁTIMA BARROS ESTIVALETE}

Universidade Federal de Santa Maria

Doutorado em Agronegócios - Universidade Federal do Rio Grande do Sul (UFRGS) Orcid: http://orcid.org/0000-0002-3277-8613 / E-mail: vaniaestivalete@ufsm.br

\section{MAURI LEODIR LÖBLER}

Universidade Federal de Santa Maria

Doutor em Administração pela Universidade Federal do Rio Grande do Sul.

Orcid: http://orcid.org/0000-0002-0244-6351 / E-mail: mllobler@gmail.com

Submissão: 09/09/2019. Revisão: 13/05/2020. Aceite: 07/07/2020. Publicação: 03/08/2020. DOI: http://dx.doi.org/10.22277/rgo.v13i3.5086

\section{RESUMO}

A partir da ampla disseminação e utilização da internet para diferentes finalidades, torna-se necessário investigar aspectos individuais que afetam a propensão das pessoas em adotar produtos e serviços tecnológicos. Nesse sentido, este artigo teve como objetivo verificar a influência dos valores pessoais na prontidão tecnológica e na Intenção de Continuidade de Uso das tecnologias pelos jovens. Na seção teórica, foram apresentados os conceitos e abordagens sobre valores pessoais e prontidão à tecnologia, assim como a fundamentação para a proposição das hipóteses do estudo. Uma survey foi aplicada aos estudantes e para o desenvolvimento do instrumento de coleta de dados foram utilizados três modelos teóricos: i) Questionário de Perfis de Valores - PQV (SCHWARTZ, 2005; SCHWARTZ et al., 2001); ii) Prontidão para o Uso da Tecnologia - TRI (PARASURAMAN, 2000); e, iii) Modelo de Pós Aceitação de Sistema de Informação - PAM (BHATTACHERJEE, 2001). A análise dos resultados demonstrou que seis hipóteses foram confirmadas, indicando que a Continuidade de uso é influenciada pelo Otimismo, Inovatividade e valores de Abertura à Mudança. Além disso, os valores pessoais de Abertura à Mudança e Conservação impactam positivamente os condutores e um dos inibidores de propensão ao uso de tecnologias. Concluiu-se que os valores pessoais são fatores relevantes para a propensão de uso de tecnologias.

Palavras-chave: Comportamento. Tecnologia. Valores. 
Compreendendo a influência dos valores pessoais na prontidão e na intenção de uso de tecnologias

\begin{abstract}
From the widespread dissemination and use of the internet for different purposes, it is necessary to investigate individual aspects that affect people's propensity to adopt technological products and services. In this sense, this article has as objective to verify the influence of personal values on technological readiness and on the Intention of Continuity of Use of technologies by young. In the theoretical section, the concepts and approaches on personal values and technology readiness were presented, as well as the reasoning for proposing the hypotheses of the study. A survey was applied to students and for the development of the data collection instrument was used three theoretical models: i) Questionnaire of Profiles of Values - PQV (SCHWARTZ, 2005; SCHWARTZ et al., 2001); ii) Readiness for the Use of Technology - TRI (PARASURAMAN, 2000); and iii) Post Acceptance Model of SI - PAM (BHATTACHERJEE, 2001). The analysis of the results showed that six hypotheses were confirmed, indicating that Continuity of use is influenced by Optimism, Innovation and values related to Openness to Change. In addition, the personal values of Openness to Change and Conservation positively impact drivers and one of the inhibitors of propensity to use technologies. It was concluded that personal values are relevant factors for the propensity to use technologies.
\end{abstract}

Keywords: Behavior. Technology. Values.

\title{
1 INTRODUÇÃo
}

A partir da ampla disseminação e utilização da internet, o ambiente online tornou-se um importante canal para a comunicação interpessoal. $O$ acesso das pessoas à rede é motivado por diversas finalidades, como a realização de compras e a busca de informações a respeito de produtos e serviços (MACLENNAN et al., 2014). O consumidor, nos dias de hoje, depara-se com a dinâmica tecnológica, presente em atividades cotidianas, como serviços bancários, comércio eletrônico, serviços de alimentação e de educação (GROHMANN et al., 2014). Parasuraman (2000) salienta que o papel da tecnologia na interação de clientes versus empresa e o número de produtos e serviços baseados na tecnologia vêm crescendo rapidamente, no entanto, estes avanços, muitas vezes, não trazem benefícios esperados pelos clientes.

Mick e Fournier (1998) corroboram ao afirmarem que a tecnologia nem sempre é positiva, já que ao mesmo tempo em que gera sentimentos positivos de controle, liberdade, novidade, competência, satisfação e engajamento, também pode provocar sentimentos de caos, escravização, obsolescência, insatisfação, isolamento e desengajamento. Dessa forma, torna-se relevante investigar a propensão das pessoas em adotar produtos e serviços tecnológicos, considerando a existência de condutores e inibidores mentais relacionados ao Otimismo, Inovatividade, Desconforto e Insegurança (PARASURAMAN, 2000).

Com o intuito de compreender de uma maneira mais parcimoniosa as semelhanças e diferenças entre indivíduos, grupos, nações ou culturas, Schiffman, Sherman e Long (2003) utilizam o conceito de valor pessoal. Os valores humanos, de acordo com Schwartz e Bilsky (1987, p. 551), são definidos como "princípios ou crenças, sobre comportamentos ou estados de existência, que transcendem situações específicas, que guiam a seleção ou a avaliação de comportamentos ou eventos e que são ordenados por sua importância".

A influência dos valores pessoais sobre o comportamento do indivíduo tem sido verificada em vários contextos, como comportamento pró-ambiental (ou "verde") (SIMÕES; 
GIRALDI; OLIVEIRA, 2012), valor de marcas (BOYLE, 2003; LEÃO; SOUZA NETO; MELLO, 2007), efeito no país de origem e aspectos culturais (LENARTOWICZ; JOHNSON, 2003; GIRALDI, 2006) e como moderadores no engajamento do consumidor em comunidades de marca (MARBACH et al., 2019). No entanto, pouca pesquisa tem sido dedicada para a relação entre valores e uso da internet (SCHIFFMAN; SHERMAN; LONG, 2003).

Tendo em vista que os avanços tecnológicos propiciam impactos sobre o modo como os consumidores lidam com produtos, investigar o perfil de consumo de tecnologias é relevante para detectar novas formas de comercialização com base nas demandas apresentadas pelo público-alvo. Destaca-se que usuários jovens, como estudantes, são mais experientes com a Internet e possuem padrões de compras eletrônicas que diferem, especialmente, nos valores hedônicos e utilitários, sendo considerados consumidores online qualificados (KIM et al., 2012; SAN-MARTíN; PRODANOVA; JIMÉNEZ, 2015). Corroborando, Herrando, Jimenez-Martinez e Martin-De Hoyos (2019) demonstraram que o comportamento online da geração Z, que compreende a população nascida entre 1991 e 2000, apresenta diferenças marcantes em relação às gerações anteriores ( $\mathrm{X}$ e $\mathrm{Y}$ ).

Diante do exposto sobre as especificidades dos jovens na utilização de tecnologias e considerando que os valores pessoais se tornam os fatores mais importantes para o estudo do comportamento do consumidor, por serem orientados para o indivíduo (KAMAKURA; NOVAK, 1992), apresenta-se a seguinte questão de pesquisa: Qual a influência dos Valores Pessoais na propensão e no uso de tecnologias pelos jovens?

Este artigo tem por objetivo verificar a influência dos Valores Pessoais na Prontidão Tecnológica e na Intenção de Continuidade de Uso das tecnologias pelos jovens. Para tanto, foi realizada uma pesquisa descritiva com discentes de uma instituição de ensino superior e de um colégio politécnico. Foram utilizados três modelos teóricos, o de Prontidão para o Uso da Tecnologia - TRI (PARASURAMAN, 2000); o Questionário de Perfis de Valores - PQV (SCHWARTZ, 2005; SCHWARTZ et al., 2001); e, o Modelo de Pós Aceitação de Sistema de Informação - PAM (BHATTACHERJEE, 2001).

A mensuração das intenções comportamentais relacionadas à tecnologia é imprescindível, pois se a população de um país ou região não estiver aberta à novas Tecnologias de Informação e Comunicação (TICS), o desenvolvimento futuro desse país pode estar ameaçado (RAMÍREZ-CORREA; GRANDÓN; RONDÁN-CATALUÑA, 2020). Assim, este estudo se justifica pela relevância da temática e pela carência de estudos que investigam especificamente os valores pessoais e a prontidão tecnológica. Tal perspectiva é corroborada por uma busca realizada na base Web of Science, a qual contempla uma abrangente base de dados de periódicos revisados por pares e reconhecidos pela comunidade científica internacional (CROSSAN; APAYDIN, 2010). Foram utilizados os termos "technological readiness" e (and) "personal values", na opção tópico que compreende título, resumo e palavras-chave, sem limitar o período de anos. Os resultados mostraram 13 trabalhos, mas nenhum deles aborda conjuntamente os dois temas.

$\mathrm{O}$ artigo foi estruturado em cinco seções, iniciando com a introdução. Na sequência é apresentado o referencial teórico sobre Valores Pessoais e Prontidão Tecnológica, passando para a definição das hipóteses. Na seção seguinte, aborda-se o método de pesquisa, o instrumento de coleta e as análises estatísticas realizadas. O quarto item compreende a apresentação dos resultados em termos de perfil da amostra, validação do modelo global, teste das hipóteses e relações entre os resultados obtidos e a teoria. Por fim, as considerações finais são destacadas, incluindo as limitações do estudo e as sugestões para futuras pesquisas. 
Compreendendo a influência dos valores pessoais na prontidão e na intenção de uso de tecnologias

\section{REFERENCIAL TEÓRICO}

Nesta seção, são apresentados os conceitos e abordagens sobre valores pessoais e prontidão à tecnologia, assim como a fundamentação teórica para a proposição das hipóteses do estudo, que buscam verificar as relações entre valores pessoais, especialmente aqueles voltados abertura à mudança (Hedonismo, Estimulação e Autodeterminação) e os valores relacionados com a conservação (Tradição, Conformidade e Segurança), prontidão tecnológica e intenção de continuidade de uso de tecnologias.

\subsection{VALORES PESSOAIS}

As atitudes e comportamentos estão muito atrelados aos valores pessoais de cada indivíduo, onde estes atuam como princípios norteadores no contexto de vida das pessoas. Dessa forma, na ótica de Von Borell, Cambield e Rodrigues (2019) os valores pessoais são concepções que norteiam a vida humana, suas características e comportamentos que motivam e guiam as decisões. Corroborando, Schwartz (2005) define valores como uma orientação para as ações a serem adotadas, através de uma visão sistêmica daquilo que é necessário ser feito.

De acordo com Teixeira e Monteiro (2008), os primeiros estudos sobre valores foram no início do século XX com o trabalho de Thomas e Znaniecki, em 1918 e 1920, e com as investigações de Allport e Vernon, no ano de 1931. Considera-se que a partir dos estudos de Rokeach (1973) que essa temática ganhou notoriedade, proporcionando a popularização do assunto.

Rokeach (1973) classificou os valores pessoais em dois tipos: os valores instrumentais e os valores terminais, sendo que os primeiros descrevem comportamentos que facilitam a obtenção dos valores terminais e são relacionados a modos preferidos de conduta ou modos de comportamento, como: animado, ambicioso, amoroso, asseado, autocontrolado, capaz, corajoso, polido, honesto, imaginativo, independente, intelectual. Já os valores terminais são estados de ser preferidos ou estados psicológicos amplos, associados a estados finais desejados de existência, como: amizade verdadeira, amor maduro, auto respeito, felicidade, harmonia interior, igualdade, liberdade, segurança nacional e sentimento de realização.

Entretanto, foram as pesquisas de Schwartz e Bilsky (1987), e posteriormente com Schwartz (1992), que uma teoria de valores pautada em relações de conflito e compatibilidade deu origem a uma estrutura universal de valores. A estrutura de valores proposta por Schwartz (1992) consiste na organização de dez tipos de valores em uma estrutura circular para representar os tipos motivacionais, os fatores de segunda ordem e as relações de compatibilidade e conflito. Na estrutura, quanto mais próximo um tipo motivacional estiver de outro, maior a probabilidade de compatibilidade entre os valores e quanto mais afastado, maior a de conflito.

Schwartz (2005) postula que os valores formam um continum de motivações relacionadas, onde os dez tipos motivacionais são representados por uma estrutura circular e agrupados em duas dimensões bipolares, que capturam e indicam as relações dinâmicas de conflito e compatibilidade entre os tipos motivacionais. De um lado está Autotranscendência (Universalismo e Benevolência) versus Autopromoção (Poder e Realização). Do outro lado, está Abertura à Mudança (Estimulação, Autodeterminação e Hedonismo) versus Conservação (Tradição, Conformidade e Segurança), conforme Figura 1. 
Figura1 - Estrutura circular dos valores pessoais

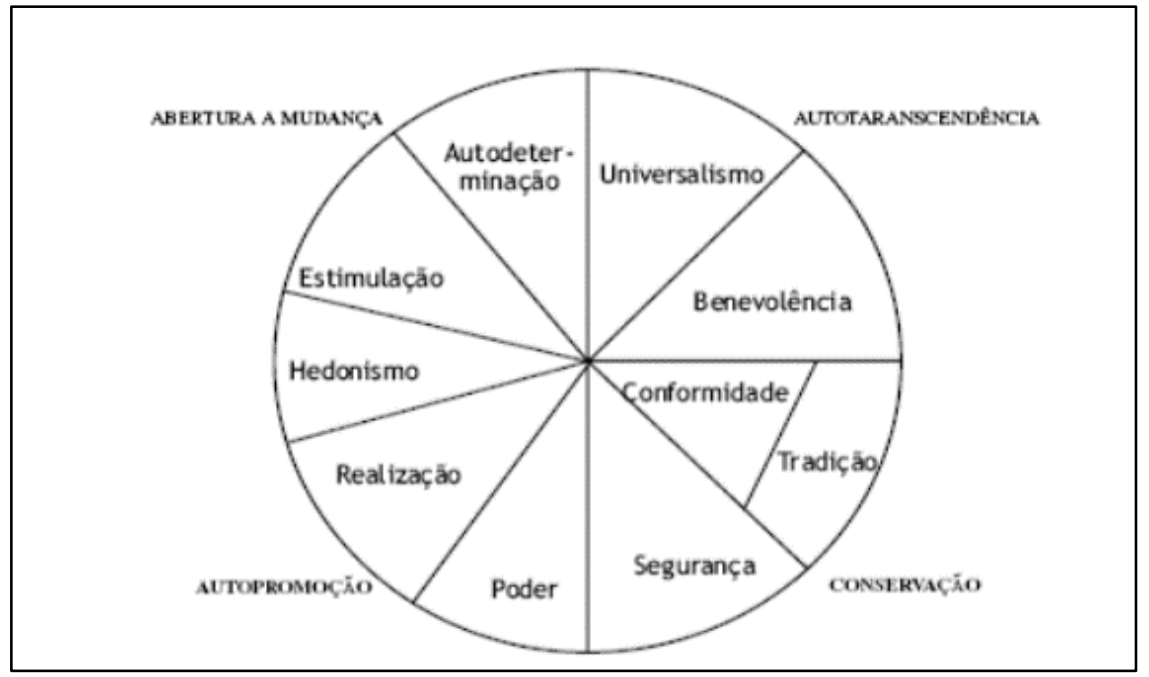

Fonte: Schwartz (2005).

Nesse contexto, o Universalismo consiste na compreensão, apreço, tolerância e atenção com o bem-estar de todas as pessoas e da natureza. Já a Benevolência é a preservação ou intensificação do bem-estar das pessoas com as quais se está em contato pessoal frequente. A Conformidade compreende restrição de ações, tendências e impulsos que possam incomodar ou ferir os outros e contrariar expectativas ou normas sociais. Quanto a Tradição, é o respeito, compromisso e aceitação dos costumes e ideias oferecidas pela cultura tradicional ou religião. Por fim, a Segurança consiste na firmeza das ações de cada indivíduo (SCHWARTZ, 2005).

Do outro lado do círculo tem-se a Autodeterminação; a Estimulação; o Hedonismo; a Realização e; o Poder. A Autodeterminação diz respeito ao pensamento independente e escolha da ação, criatividade, exploração. A Estimulação está associada com o entusiasmo, novidade e desafio na vida. Nesse sentido, cada pessoa possui uma maneira própria de se comportar e se relacionar com os outros. Essas particularidades são desenhadas ao longo da vida do indivíduo, com base em todas as experiências vividas por ele e nas interpretações atribuídas a cada momento. Por sua vez, o Hedonismo consiste no prazer e gratificação sensual para si mesmo. A Realização denomina-se como o sucesso pessoal mediante a demonstração de competência e o Poder é entendido como o status social sobre as pessoas e os recursos (SCHWARTZ, 2005).

Roccas, Schwartz e Amit (2010) atentam para os dois conflitos básicos da estrutura circular: i) Conservação versus Abertura à Mudança, sendo que os valores de Conservação enfatizam a ordem e a resistência à mudança, evitando incertezas e ambiguidades enquanto que a Abertura à Mudança preza pela ação independente, o pensamento e a prontidão para novas experiências; ii) Autopromoção versus Autotranscendência, destacando-se que os indivíduos que atribuem grande importância aos valores de Autopromoção são motivados a buscar status e prestígio social ao controlar pessoas e recursos, ao passo que os valores da Autotranscendência priorizam auxiliar os interesses dos outros, visando justiça social e igualdade para todas as pessoas.

\subsection{PRONTIDÃO TECNOLÓGICA}

O contexto mercadológico mundial atual demanda a necessidade do uso de tecnologias, sendo imprescindível a busca por conhecimentos constantemente. A informação assume uma importância crescente, tornando-se uma necessidade para qualquer setor da 
atividade humana, devido a tantas transformações (GHESTI et al., 2019). O cotidiano apresenta, a cada momento, novos conceitos e tendências com uma intensa velocidade.

Para Falsarella e Jannuzzi (2017), a velocidade da tecnologia e da informação impressiona e exige constantes atualizações por parte das pessoas, pois esses avanços influenciam diretamente em todos os setores econômicos e nos meios sociais. Nesse contexto, Veras (2019) conceitua a tecnologia, de modo que a mesma pode ser compreendida como um produto da ciência, na qual envolve um conjunto de instrumentos, métodos e técnicas com intuito de proporcionar agilidade e soluções de forma mais efetiva para os problemas sociais, bem como no âmbito organizacional.

Na concepção de Laudon e Laudon (2004) a Tecnologia da Informação (TI) pode ser entendida como um conjunto formado por hardware e software e utilizado para coletar, processar, armazenar e disseminar informação para suporte às decisões. Os procedimentos, métodos e equipamentos usados para processar a informação e comunicá-la aos interessados constituem a Tecnologia de Informação e Comunicação (TIC). Balancieri et al. (2005) destacam que as novas TICs propiciaram uma gama de novas possibilidades para a análise de redes sociais, considerando a relevância do advento da internet.

É notório que as tecnologias virtuais se tornaram uma ferramenta poderosa para exposição de opiniões e experiências em relação a produtos e marcas e os indivíduos têm utilizado, cada vez mais, as mídias digitais como modo para externar frustrações, reclamações ou elogios às empresas (VAZ, 2008). Dessa forma, as visões individuais (percepções, crenças, sentimentos e motivações) remetem à aspectos favoráveis e desfavoráveis a respeito de produtos e serviços tecnológicos.

Veras (2019) discorre sobre esses aspectos, salientando que num contexto de oportunidades proporcionadas pela tecnologia, é necessária uma reflexão quanto aos aspectos que tem influenciado o comportamento das pessoas, considerando fatores como interações sociais, praticidades de comunicação, entretenimento, dentre outros. Além disso, Parasuraman e Colby (2002) destacam que existem assimetrias no comportamento do consumidor de produtos de alta tecnologia.

As pessoas podem demonstrar propensão para adotar novas tecnologias, caracterizando a prontidão tecnológica, ao passo que consideram o estado resultante de condutores e inibidores mentais que, em conjunto, determinam a predisposição individual para interagir com produtos e serviços baseados em tecnologia (PARASURAMAN, 2000). Na perspectiva de Parasuraman e Colby (2002), a prontidão tecnológica apresenta características específicas: a) varia de um indivíduo para outro: o percurso levado até a adoção da tecnologia depende do perfil de cada pessoa, o que resultará em prontidão com graus de manifestação diversos; b) multifacetada, ou seja, o grau de uma pessoa é estabelecido de acordo com suas diferentes crenças; $c$ ) presume e esclarece a resposta do consumidor de novas tecnologias, isto é, busca prever e explicar o percentual de adoção de tecnologia, bem como sua forma de uso.

A atitude do consumidor em relação a produtos tecnológicos é influenciada por facetas negativas e positivas, as quais estão relacionadas a sentimentos positivos, negativos e/ou neutros referentes à adoção de tecnologia. Os sentimentos que contribuem para o ser humano adotar ou não as tecnologias são compreendidos em quatro dimensões (PARASURAMAN, 2000; PARASURAMAN; COLBY, 2002): Otimismo, dimensão definida como uma visão positiva da tecnologia e a crença de que ela propicia às pessoas maior controle, flexibilidade e eficiência nas suas vidas; caráter inovador, tendência de um indivíduo ser pioneiro em tecnologia e líder de pensamento; Desconforto, falta de controle percebido sobre 
a tecnologia e o sentimento de ser oprimido por ela; e, Insegurança, refere-se a desconfiança e ceticismo a respeito da capacidade da tecnologia funcionar corretamente. Dessa forma, um indivíduo altamente otimista e com forte capacidade de inovação e baixo desconforto e insegurança tende a utilizar novas tecnologias (RAMIREZ-CORREA; GRANDON; RONDÁNCATALUÑA, 2020).

Para mensurar a prontidão tecnológica, Parasuraman (2000) e Parasuraman e Colby (2001) desenvolveram o Índice de Prontidão à Tecnologia (Technology Readiness Index - TRI), que se constituiu num instrumento de medida da prontidão para a tecnologia. Os construtos da prontidão foram estabelecidos com base nas características de condutores (Otimismo e Inovatividade) e inibidores (Desconforto e Insegurança) para a adoção da tecnologia.

De acordo com Souza e Luce (2005), a utilização do TRI se caracteriza como um instrumento de mensuração das atitudes e crenças dos indivíduos, sendo útil para predizer comportamentos de adoção, identificar tipos distintos de indivíduos e prever comportamentos futuros de consumidores. Conforme observam Mukerjee, Deshmukh e Prasad (2018), o TRI reflete a crença de um cliente em relação à uma tecnologia específica, mas não indica sua competência em utilizá-la.

Ao passo que as compras realizadas em plataformas eletrônicas experimentam um crescimento constante, estudos de mercado demonstram que o aumento da satisfação do cliente torna-se um processo mais lento (FREED; ANDERSON, 2012). Bijmolt, Huizingh e Krawczyk (2014) atentam para o fato de que o ambiente online não contempla a maioria dos elementos de interação humana que definem as experiências de serviços tradicionais. Nesse sentido, Pereira (2002) salienta que a adoção de tecnologia deve ser estudada do ponto de vista do usuário e não das atividades de implantação ou de fatores ligados à tecnologia em si. Dessa forma, compreender aspectos individuais que refletem no comportamento em ambientes virtuais pode contribuir na dinâmica mercadológica e no atendimento das expectativas dos usuários.

\subsection{HIPÓTESES DO ESTUDO}

Este estudo pauta-se em dez hipóteses que buscam verificar se os valores voltados a Abertura à Mudança (Hedonismo, Estimulação e Autodeterminação) afetam os fatores Otimismo e Inovatividade; e, os valores relacionados com a Conservação (Tradição, Conformidade e Segurança) impactam os fatores Desconforto e Insegurança, além da influência destes na Intenção de Continuidade de Uso de tecnologia, conforme apresentado na Figura 2.

O impacto das Tecnologias da Informação e Comunicação (TICs) não são uniformes e dependem de variáveis sócio históricas, aspectos individuais e organizacionais em níveis macro e micro sociais: governo, sociedade, família, entre outras organizações sociais nas quais os indivíduos se estruturam (PASSERINO; PASQUALOTTI, 2006). Dessa forma, ao considerar, em nível micro, uma organização social como a família, o impacto das tecnologias é diferente para cada um dos seus membros.

A associação entre valores humanos e adoção de tecnologia foi investigada por pesquisadores. Wang, Dou e Zhou (2008) utilizaram cinco tipos de valores pessoais da teoria de Schwartz (Conformidade, Segurança, Tradição, Autodeterminação e Estimulação) para entender o relacionamento entre atitudes de consumo e adoção de novos produtos. Os resultados indicaram que o valor pessoal "Tradição" se relaciona negativamente com a adoção de novos produtos e os valores pessoais "Autodeterminação" e "Estimulação" relacionam-se positivamente com a adoção de novos produtos. Isomursu et al. (2011), ao observarem 
diferentes grupos, verificaram que os valores pessoais são uma parte relevante no que tange a explicação de aceitação ou não de determinada tecnologia. Na pesquisa realizada por Dagfous, Petrof e Pons (1999) foi demonstrado que altos níveis de valor de segurança dificultam a adoção de novos produtos entre os consumidores internacionais.

Figura 2 - Hipóteses do estudo

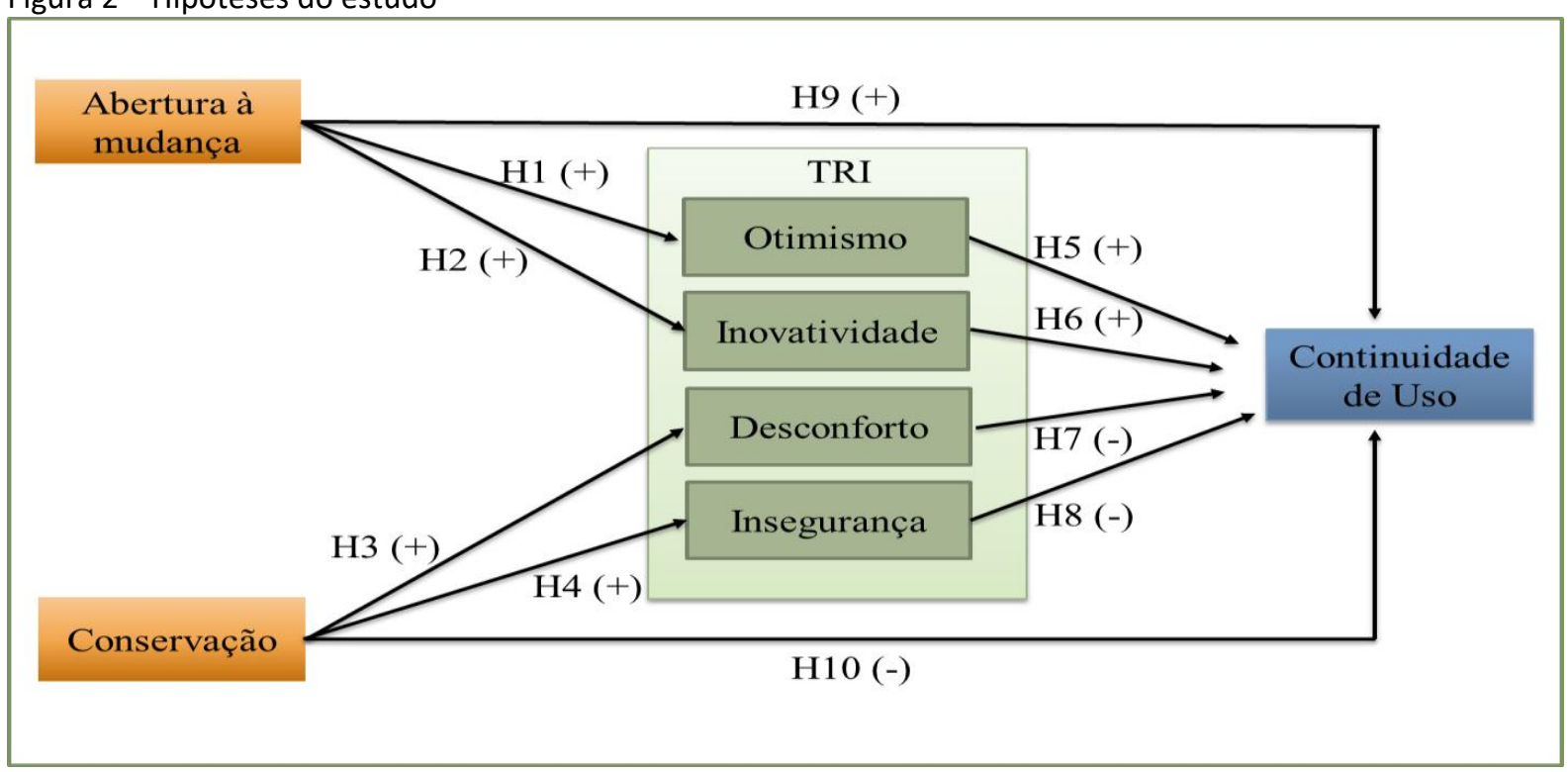

Fonte: Elaborada pelos autores

Dessa forma, busca-se compreender a propensão do indivíduo para uso de tecnologia a partir da sua percepção de valores pessoais. Visando associar aspectos positivos e negativos em relação à tecnologia, considera-se os valores associados a Abertura à Mudança (Hedonismo, Estimulação e Autodeterminação) que tendem a influenciar a propensão para uso de novas tecnologias; e, os valores relacionados com a Conservação (Tradição, Conformidade e Segurança) que tendem a inibir o uso de novas tecnologias.

De acordo com Roccas, Schwartz e Amit (2010), valores de Abertura à Mudança priorizam a ação independente, o pensamento e a prontidão para novas experiências, sendo que os indivíduos que valorizam tais valores são motivados a explorar, descobrir e buscar situações novas e inesperadas. Tendo em vista que os indivíduos podem demonstrar propensão para adotar novas tecnologias a partir de fatores condutores (PARASURAMAN, 2000; RAMIREZ-CORREA; GRANDON; RONDÁN-CATALUÑA, 2020), as hipóteses H1 e H2 buscam testar as relações entre valores de Abertura à Mudança e os condutores Otimismo e Inovatividade.

H1: Os valores voltados a Abertura à Mudança afetam positivamente o Otimismo.

H2: Os valores voltados a Abertura à Mudança afetam positivamente a Inovatividade.

Conforme destacam Roccas, Schwartz e Amit (2010), as pessoas com alto nível de Conservação estão menos preparadas para novas experiências, uma vez que aderem a crenças, costumes ou tradições que podem afetar seu engajamento online. Corroborando, Marbach et al. (2019) verificaram que o indivíduo que possui baixos valores de Conservação apresenta maiores níveis de envolvimento em comunidades virtuais. Nesta perspectiva, os valores de Tradição, Conformidade e Segurança tendem a influenciar negativamente a adoção de novas tecnologias, contribuindo com a percepção acerca dos fatores que inibem a utilização das tecnologias.

H3: Os valores voltados Conservação afetam positivamente o Desconforto.

H4: Os valores voltados à Conservação afetam positivamente a Insegurança. 
Estudos apontam que a prontidão tecnológica influencia a intenção comportamental dos usuários, especialmente, o uso continuado (CHEN; CHEN; CHEN, 2009; GROHMANN et al., 2014). Assim, as relações entre os constructos do TRI e a Intenção de Continuidade de Uso são propostas nas quatro hipóteses seguintes. Considerando que a Intenção de Continuidade de Uso da tecnologia se refere à intenção do indivíduo para o uso contínuo do Sistema de Informação (BHATTACHERJEE, 2001), buscou-se verificar qual a influência dos antecedentes condutores (Otimismo e Inovatividade) e inibidores (Desconforto e Insegurança) de tecnologia. A quinta hipótese pressupõe que se o Otimismo é uma visão positiva da tecnologia, seu efeito na Intenção do indivíduo de continuar a utilizar a tecnologia será positivo.

H5: O Otimismo do indivíduo em relação à tecnologia afeta positivamente a Intenção de Continuidade de Uso da tecnologia.

De forma semelhante, o caráter inovador poderá influenciar positivamente a Intenção de Continuidade de Uso de tecnologias, uma vez que pessoas com características inovativas estão dispostas à utilização de tecnologia. Dessa forma, propõem-se a sexta hipótese:

H6: A Inovatividade do indivíduo afeta positivamente a Intenção de Continuidade de Uso da tecnologia.

A sétima hipótese possui o Desconforto como antecedente. Conforme Parasuraman (2000), este constructo envolve a percepção de falta de controle sobre a tecnologia e um sentimento de estar sendo pressionado ou oprimido por ela. Então, se o sentimento de desconforto é percebido numa situação, o indivíduo tende a evitar a repetição do acontecimento, ou seja, não estará disposto a continuar seu uso de tecnologia.

H7: O Desconforto do indivíduo em relação à tecnologia afeta inversamente a Intenção de Continuidade de Uso da tecnologia.

A Insegurança também pode ser relacionada inversamente a intenção de continuidade, uma vez se a pessoa se sente insegura numa situação, tende a evitar tal sentimento numa nova ocasião. Assim, a oitava hipótese parte desse pressuposto.

H8: A Insegurança do indivíduo em relação à tecnologia afeta inversamente a Intenção de Continuidade de Uso da tecnologia.

As últimas hipóteses buscam verificar a associação entre os valores pessoais e a Intenção de Continuidade de Uso de tecnologia. Partindo da concepção de que os valores que demonstram Abertura à Mudança por parte das pessoas tendem a influenciar positivamente o uso de tecnologia e, consequentemente, a Intenção de Continuidade, tem-se a nona hipótese:

H9: Os valores voltados a Abertura à Mudança afetam positivamente a Intenção de Continuidade de Uso da tecnologia.

A décima hipótese evidencia que os valores relacionados com a Conservação vão influenciar inversamente a Intenção de Continuidade de Uso:

H10: Os valores voltados Conservação afetam inversamente a Intenção de Continuidade de Uso da tecnologia.

\section{MÉTODO DO ESTUDO}

Este estudo tem por objetivo geral verificar a influência dos valores pessoais na prontidão tecnológica e na Intenção de Continuidade de Uso das tecnologias pelos jovens. A pesquisa caracteriza-se como descritiva, de caráter quantitativo. A pesquisa descritiva visa informar o pesquisador sobre situações, fatos, opiniões ou comportamentos da população analisada, buscando mapear a distribuição de um fenômeno (TRIVIÑOS, 2007). 
Para desenvolvimento do instrumento de coleta de dados (Apêndice A) foram utilizados três modelos teóricos. O primeiro refere-se ao Questionário de Perfis de Valores - Portrait Questionnaire Value (PQV), construído por Schwartz e colaboradores (SCHWARTZ, 2005; SCHWARTZ et al., 2001). Schwartz (2005) postula que os valores formam um continuum de motivações relacionadas, onde os dez tipos motivacionais são representados por uma estrutura circular e agrupados em duas dimensões bipolares, que capturam e indicam as relações dinâmicas de conflito e compatibilidade entre os tipos motivacionais. De um lado está Autotranscendência (Universalismo e Benevolência) versus Autopromoção (Poder, Realização, Hedonismo). Do outro, Abertura à mudança (Hedonismo, Estimulação e Autodeterminação) versus Conservação (Tradição, Conformidade e Segurança). Nesta investigação, optou-se por utilizar a segunda dimensão bipolar: Abertura à mudança versus Conservação.

A segunda parte do instrumento compreendeu o Índice de Prontidão Tecnológica (TRI), de Parasuraman (2000), validado para o contexto brasileiro por Souza e Luce (2003), sendo considerados os quatro constructos do TRI: Otimismo, Inovatividade, Desconforto e Insegurança. O terceiro modelo utilizado foi o Modelo de Pós Aceitação de SI (PAM), desenvolvido por Bhattacherjee (2001), do qual se considerou o constructo intenção de continuidade de uso.

Os questionários da survey foram aplicados a estudantes de uma Universidade Federal e de um Colégio Politécnico, localizados em duas cidades do estado do Rio Grande do Sul. Foi selecionada uma amostra não probabilística de 250 estudantes e, ao final do processo de coleta de dados, obteve-se 241 questionários válidos que foram totalmente preenchidos.

A coleta de dados ocorreu via questionário, aplicado de forma presencial, o qual foi composto por quatro seções. A primeira delas compreendia trinta e seis questões referentes ao modelo TRI (PARASURAMAN, 2000; PARASURAMAN; COLBY, 2001). A segunda parte consistiu em três afirmações do constructo intenção de continuidade de uso, originadas no Modelo de Pós Aceitação de SI (PAM), de Bhattacherjee (2001). Na sequência, utilizou-se dezoito afirmações do Questionário de Perfis de Valores (PQV), de Schwartz e colaboradores (SCHWARTZ, 2005; SCHWARTZ et al., 2001), voltadas à dimensão bipolar: Abertura à mudança versus Conservação. A última seção apresentou questões referentes ao perfil dos respondentes, como gênero, idade, grau de escolaridade e renda familiar.

Dessa forma, o instrumento de coleta de dados contou com cinquenta e sete afirmações, além das questões sobre o perfil. Nas duas primeiras seções, os respondentes deveriam posicionar-se entre discordo totalmente (1) ou concordo totalmente (5), através de uma escala tipo Likert. Na terceira parte, os pesquisados necessitavam avaliar o quanto cada uma das pessoas apontadas nas afirmações era semelhante com suas próprias características, tendo como opções de resposta: 1 - não se parece nada comigo; 2 - não se parece comigo; 3 - se parece mais ou menos comigo; 4 - se parece comigo; 5 - se parece muito comigo.

Os dados coletados foram tabulados no Microsoft Excel e analisados estatisticamente através dos softwares Statistical Package for the Social Sciences ${ }^{\mathrm{TM}}$ - SPSS 21.0 e Analysis of Moment Structures - SPSS AMOS. As análises estatísticas realizadas foram: análises de frequência visando caracterizar a amostra; análise fatorial exploratória para purificação dos dados e construção do modelo global inicial. Na sequência, através da modelagem de equações estruturais, foram realizados os seguintes procedimentos estatísticos: análise fatorial confirmatória para a validação do modelo, através dos índices de ajuste, teste de unidimensionalidade, validade convergente e validade divergente; e, teste das hipóteses. 


\section{ANÁLISE E DISCUSSÃO DOS DADOS}

A amostra do estudo foi composta por duzentos e quarenta e um respondentes, sendo cento e trinta e três homens $(55,18 \%$ do total) e cento e oito mulheres ( $44,81 \%$ do total), tendo uma distribuição relativamente homogênea, sem o predomínio de um dos gêneros. Em relação à faixa etária, o predomínio foi de pessoas entre 18 e 25 anos, representando 78,4\% dos respondentes ( $n=189$ ), na sequência, aparecem as seguintes faixas etárias: de 26 anos a 35 anos (13,7 \% da amostra) e menores de 18 anos (3,7\% da amostra). Respondentes com idade igual ou superior a 36 anos, foram responsáveis por $4,2 \%$ da amostra.

Considerando o grau de instrução, a maioria respondeu ensino superior incompleto, $79,25 \%$ da amostra ( $n=191)$, seguido do ensino médio, 10,8\% ( $n=26)$. Dados que corroboram o fato de estudantes de graduação e ensino técnico terem respondido o questionário. Complementarmente, quinze pessoas $(6,2 \%)$ possuem ensino superior completo e nove respondentes $(3,7 \%)$ estão realizando ou já concluíram pós-graduação. Quanto à renda mensal familiar, a maioria dos respondentes $(n=106)$ está compreendida na faixa de $\mathrm{R} \$ 955,00$ a $R \$ 2.500,00$, representando $44 \%$ do total da amostra. Na sequência, a faixa de mais de $R \$$ $2.501,00$ a $R \$ 5.000,00$, foi a segunda mais citada $(n=70)$.

Através da Análise Fatorial Exploratória (AFE), realizada para cada um dos modelos (Tabela 1), foram identificadas as cargas fatoriais e comunalidades das variáveis do modelo. Pelo critério de exclusão das variáveis com cargas e comunalidades inferiores a 0,50 (HAIR JR. et al., 2009) foram retiradas as seguintes variáveis: do Índice de Prontidão Tecnológica - tri1, tri3, tri5, tri10, tri12, tri22 e tri32.

Para fins de análise da escala de Valores Pessoais, foram considerados os constructos: Abertura à Mudança, que compreende os valores Autodeterminação (v1, v11, v22 e v34), Estimulação (v6, v15 e v30) e Hedonismo (v10, v26 e v37); e, fator Conservação, que envolve os valores Segurança (v5, v14, v21, v31 e v35), Conformidade (v7, v16, v28 e v36) e Tradição ( v9, v20, v25 e v38). Devido a comunalidade inferior a 0,50 foi excluída a variável V31 ("Ela se esforça para não ficar doente. Estar saudável é muito importante para ela").

A Análise Fatorial Exploratória realizada para cada modelo foi satisfatória, visto que os valores do KMO foram superiores a 0,50, conforme recomendado por Malhotra (2011) e os testes de esfericidade de Barlett foram todos significativos. O menor valor de KMO foi para a Intenção de Continuidade de Uso $(K M O=0,600)$ e o maior valor para o modelo TRI (KMO = $0,787)$. Além disso, foram atendidos os pressupostos: i) não existência de variáveis altamente correlacionadas na matriz de correlação; e, ii) matriz anti-imagem, verificou-se que os valores apresentados na diagonal da matriz são maiores que 0,50 , sendo o menor valor obtido de 0,549 .

A partir das informações resultantes da AFE foi construído o modelo estrutural inicial e realizada a Modelagem de Equações Estruturais para Análise Fatorial Confirmatória (AFC) e o Teste de Hipóteses, através do software Amos. A Análise Fatorial Confirmatória possui o intuito de validar o modelo global através da análise dos índices de ajuste, confiabilidade dos constructos, unidimensionalidade do modelo, validade convergente e validade divergente (HAIR JR. et al., 2009).

A melhoria dos índices de ajuste é visualizada na Tabela 2 , sendo que o modelo inicial teve os seguintes índices: chi-quadrado de 2276,17 com 1367 graus de liberdade; $\mathrm{X}^{2} / \mathrm{gl}=1,66$; $p$-value =0,000; RMSEA=0,053; RMR=0,108; $\mathrm{GFI}=0,740 ; \mathrm{NFI}=0,467 ; \mathrm{RFI}=0,442 ; \mathrm{IFI}=0,687$; $\mathrm{TLI}=0,665 ; \mathrm{CFI}=0,680$. Com exceção do RMSEA, os índices do modelo inicial não atenderam aos critérios de ajuste (RMSEA e RMR $<0,10$ e demais índices $>0,90$ ). Assim, foram realizadas melhorias no modelo visando obter índices satisfatórios. 
Compreendendo a influência dos valores pessoais na prontidão e na intenção de uso de tecnologias

Tabela 1 - Resultado da análise fatorial exploratória

\begin{tabular}{|c|c|c|c|c|c|c|c|c|c|c|c|}
\hline Modelo & Item & $\begin{array}{c}\text { Carga } \\
\text { pad. }\end{array}$ & КМO & $A V E$ & Alpha & Modelo & Item & $\begin{array}{c}\text { Carga } \\
\text { pad. }\end{array}$ & КМО & $A V E$ & Alpha \\
\hline \multirow{29}{*}{$\begin{array}{l}\text { Índice de } \\
\text { Prontidão } \\
\text { Tecnológica } \\
\text { (TRI) }\end{array}$} & tri2 & 0,778 & & & & \multirow{3}{*}{$\begin{array}{l}\text { Intenção de } \\
\text { continuidade }\end{array}$} & ic1 & 0,807 & \multirow{3}{*}{0,600} & \multirow{3}{*}{54,59} & \multirow{3}{*}{0,562} \\
\hline & tri4 & 0,730 & & & & & ic2 & 0,741 & & & \\
\hline & tri6 & 0,670 & & & & & ic3 & 0,661 & & & \\
\hline & tri7 & 0,733 & & & & \multirow{26}{*}{$\begin{array}{c}\text { Valores } \\
\text { (Mudança e } \\
\text { Conservação) }\end{array}$} & v1 & 0,668 & \multirow{26}{*}{0,717} & \multirow{26}{*}{58,78} & \multirow{26}{*}{0,747} \\
\hline & tri8 & 0,764 & & & & & v5 & 0,640 & & & \\
\hline & tri9 & 0,611 & & & & & v6 & 0,593 & & & \\
\hline & tri11 & 0,600 & & & & & v7 & 0,548 & & & \\
\hline & tri13 & 0,533 & & & & & v9 & 0,664 & & & \\
\hline & tri14 & 0,788 & & & & & v10 & 0,694 & & & \\
\hline & tri15 & 0,752 & & & & & v11 & 0,585 & & & \\
\hline & tri16 & 0,653 & & & & & v14 & 0,640 & & & \\
\hline & tri17 & 0,673 & & & & & v15 & 0,503 & & & \\
\hline & tri18 & 0,681 & & & & & v16 & 0,718 & & & \\
\hline & tri19 & 0,652 & & & & & v20 & 0,523 & & & \\
\hline & tri20 & 0,690 & \multirow[t]{15}{*}{0,787} & \multirow[t]{15}{*}{58,98} & \multirow[t]{15}{*}{0,751} & & v21 & 0,715 & & & \\
\hline & tri21 & 0,639 & & & & & $\mathrm{v} 22$ & 0,663 & & & \\
\hline & tri23 & 0,717 & & & & & v25 & 0,715 & & & \\
\hline & tri24 & 0,672 & & & & & v26 & 0,715 & & & \\
\hline & tri25 & 0,556 & & & & & v28 & 0,508 & & & \\
\hline & tri26 & 0,644 & & & & & v30 & 0,723 & & & \\
\hline & tri27 & 0,662 & & & & & v34 & 0,531 & & & \\
\hline & tri28 & 0,771 & & & & & v35 & 0,789 & & & \\
\hline & tri29 & 0,755 & & & & & v36 & 0,614 & & & \\
\hline & tri30 & 0,734 & & & & & v37 & 0,772 & & & \\
\hline & tri31 & 0,749 & & & & & v38 & 0,543 & & & \\
\hline & tri33 & 0,630 & & & & & & & & & \\
\hline & tri34 & 0,673 & & & & & & & & & \\
\hline & tri35 & 0,802 & & & & & & & & & \\
\hline & tri36 & 0,501 & & & & & & & & & \\
\hline
\end{tabular}

Fonte: Elaborada pelos autores

O modelo final (Figura 3) apresentou os índices: chi-quadrado de 442,83 com 334 graus de liberdade; $\mathrm{X}^{2} / \mathrm{gl}=1,32 ; p$-value $=0,000 ; \mathrm{RMSEA}=0,037 ; \mathrm{RMR}=0,090 ; \mathrm{GFI}=0,885 ; \mathrm{NFI}=$ 0,$761 ; \mathrm{RFI}=0,729 ; \mathrm{IFI}=0,928 ; \mathrm{TLI}=0,916 ; \mathrm{CFI}=0,925$. Apenas o GFI, NFI e RFI ficaram abaixo de 0,90, considerado como limite inferior desejável (HAIR JR. et al., 2009), os demais itens satisfizeram os critérios de ajuste do modelo (RMSEA e RMR $<0,10$ e demais índices $>0,90$ ).

Para a obtenção deste ajuste, foi necessária a exclusão de vinte e seis variáveis com cargas fatoriais inferiores a 0,50: V9; V34; V1; tri18; tri20; tri35; V22; V14; V35; tri19; tri21; V21; V36; V38; tri33; tri4; tri2; V28; V7; V5; tri23; V6; V15; tri34; V11 e V30.

Além disso, foram incluídas correlações entre os erros: $50 \leftrightarrow 60 ; 31 \leftrightarrow 36 ; 49 \leftrightarrow 60$; $6 \leftrightarrow 60,9 \leftrightarrow 60$ e $13 \leftrightarrow 25$. As correlações adicionadas se referem ao desconforto (erro 60 ) estar associado positivamente com a insegurança (erro 50), ou seja, quanto maior a tendência de uma pessoa estar desconfortável com a tecnologia, maior será o sentimento de insegurança, e vice-versa. Ademais, uma variável (tri36 - "Quando eu forneço informação a uma máquina ou pela internet, nunca posso ter certeza de que ela, realmente, chegou ao destino certo") pertencente ao fator insegurança se correlacionou com o fator desconforto, indicando receio, cuidado e insegurança dos respondentes quanto a utilização de tecnologias. 
Daiane Lindner Radons, Carla Rosane Da Costa Sccott, Vania De Fátima Barros Estivalete e Mauri Leodir Löbler

Tabela 2 - Evolução do Modelo

\begin{tabular}{l|c|c}
\hline Indicador & Modelo Inicial & Modelo Final \\
\hline Chi-quadrado $\left(\mathrm{X}^{2}\right)$ & 2276,17 & 442,83 \\
\hline Graus de Liberdade $(\mathrm{gl})$ & 1367 & 334 \\
\hline $\mathrm{X}^{2} / \mathrm{gl}$ & 1,66 & 1,32 \\
\hline$p$-value & 0,000 & 0,000 \\
\hline RMSEA & 0,053 & 0,037 \\
\hline RMR & 0,108 & 0,090 \\
\hline GFI & 0,740 & 0,885 \\
\hline NFI & 0,467 & 0,761 \\
\hline RFI & 0,442 & 0,729 \\
\hline IFI & 0,687 & 0,928 \\
\hline TLI & 0,665 & 0,916 \\
\hline CFI & 0,680 & 0,925 \\
\hline FOnte: Elabod
\end{tabular}

Fonte: Elaborada pelos autores

Um valor do fator Mudança, um que remete ao hedonismo (V26 - "Aproveitar os prazeres da vida é importante para ela. Ela gosta de se mimar") e outro valor da Conservação, que envolve tradição (V25 - "Ela acha que é melhor fazer as coisas de maneira tradicional. É importante para ela manter os costumes que aprendeu") se correlacionaram de forma positiva, demonstrando que aproveitar a vida de forma hedônica pode estar associada aos costumes aprendidos. Evidencia-se, assim, que o prazer pode ser percebido pelos participantes ao prezar pelo tradicional.

Figura 3 - Resultado da Modelagem de Equações Estruturais

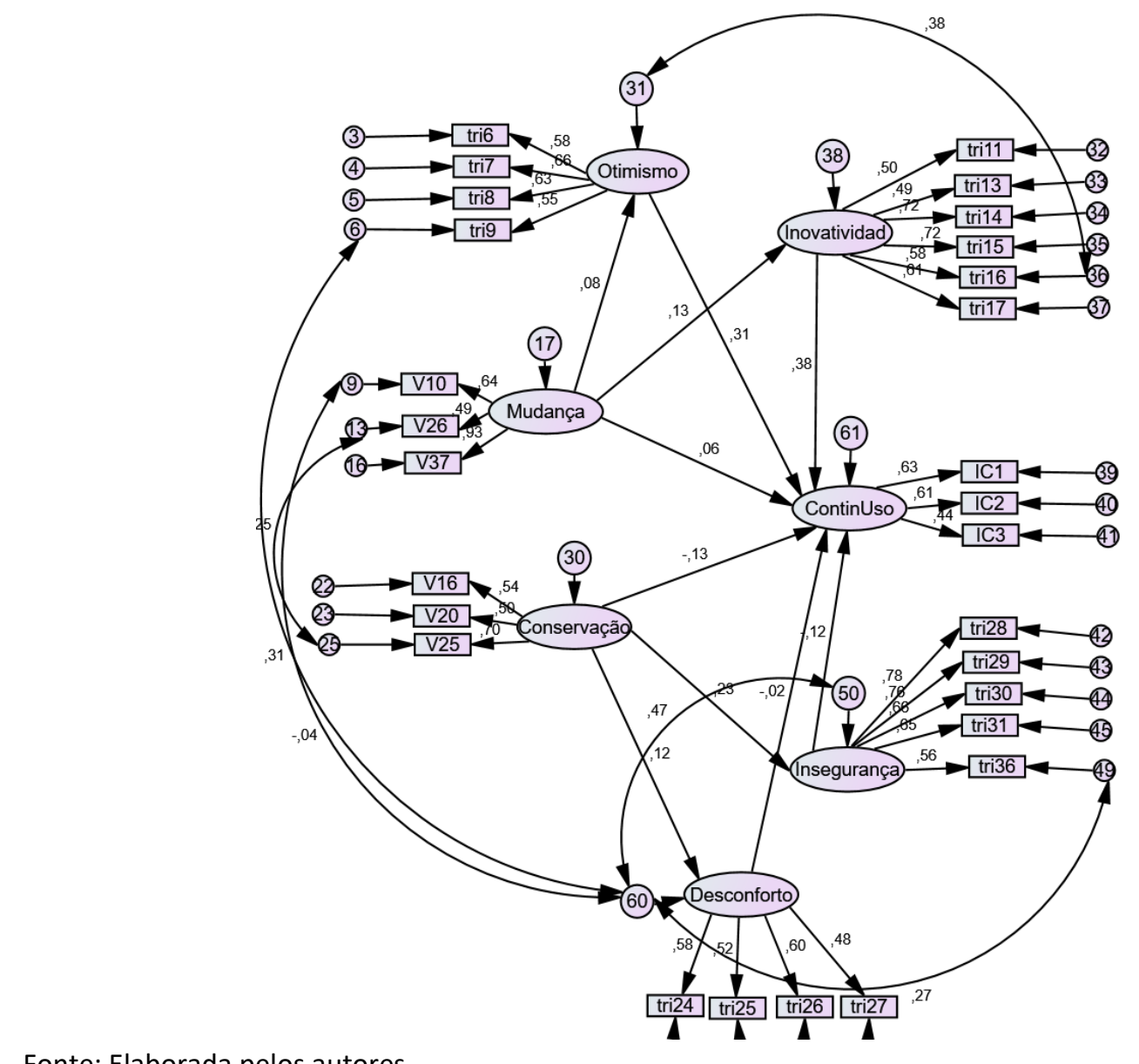

Fonte: Elaborada pelos autores 
Uma correlação positiva foi percebida entre o fator Desconforto e uma variável (tri9 "Aprender sobre tecnologia pode ser tão recompensador quanto a própria tecnologia") do Otimismo, mostrando a necessidade de compreensão da tecnologia e suas implicações, por meio da aprendizagem, que tende a contribuir com situações desfavoráveis ao uso de tecnologias. Já uma associação negativa foi observada entre Desconforto e a variável V10 (“Ela procura todas as oportunidades para se divertir. É importante para ela fazer coisas que the dão prazer") do fator Mudança, demonstrando que aproveitar todas as oportunidades de diversão diminui a percepção de controle e vice-versa.

Por fim, a variável tri16 ("Eu gosto do desafio de entender equipamentos de alta tecnologia"), do fator Inovatividade apresentou correlação positiva com o fator Otimismo, corroborando o fato de que estes fatores são considerados condutores da propensão à tecnologia.

Para verificação da confiabilidade dos constructos, foi utilizado o alpha de Cronbach, tendo como referência satisfatória, valores acima de 0,60, conforme indica Malhotra (2011). Outros autores, como Pestana e Gageiro (2000), consideram que em pesquisas de ciências sociais, valores de acima de 0,50 são aceitáveis. Os valores obtidos nos constructos do modelo (Tabela 1), variaram de 0,562 (Continuidade de Uso) a 0,751 (modelo TRI), demonstrando-se adequados. Desta forma, a confiabilidade dos constructos do modelo foi constatada.

A unidimensionalidade e a validade convergente do modelo foram comprovadas com as informações da Tabela 4. O maior erro obtido foi de 0,248 (V25), assim, todos os resíduos padronizados (erro) foram inferiores a $2,58(p<0,05)$ e a unidimensionalidade foi comprovada. A validade convergente é analisada através das cargas fatoriais padronizadas que, além de serem superiores a 0,50, para um nível de confiança de 0,01, devem apresentar $t$-valor igual ou superior a 2,33. A menor carga fatorial, considerando a realização da Análise Fatorial Exploratória (Tabela 1), foi de 0,501 (para a variável tri36), valor bem próximo de 0,50. Já o menor t-valor foi de 4,507, para a variável V25, portanto, a validade convergente do modelo também foi comprovada.

Por fim, para analisar a validade discriminante, foi realizado o cálculo de correlações entre os constructos do modelo (Correlações de Pearson) e seus resultados encontram-se na Tabela 5. Parte das correlações não foram significativas, porém, as correlações significativas foram inferiores a 0,90, critério apontados por Hair Jr. et al. (2009) para que haja validade discriminante. A maior correlação encontrada foi entre os fatores Desconforto e Insegurança, com valor de 0,402. Além disto, o quadrado das correlações (parte superior da matriz) é superior a variância extraída pelo fator. A menor variância extraída (Tabela 1) foi de 54,59\%, no fator Intenção de Continuidade de Uso, e a maior correlação ao quadrado foi de $16,1 \%$ (entre Insegurança e Desconforto). Assim, a validade discriminante foi comprovada através de ambos os procedimentos. Reitera-se que nem todas as correlações foram significativas e, portanto, a validade discriminante não foi totalmente confirmada.

A maior média foi obtida pelo construto Intenção de Continuidade $(4,16)$, seguido do Otimismo $(3,69)$, Mudança $(3,62)$ e Desconforto $(3,61)$. Tendo em vista que a escala compreendia valores de 1 (discordo totalmente) a 5 (concordo totalmente), as médias foram superiores a 2,5 , evidenciando concordância pelos respondentes a respeito das afirmações e, consequentemente, dos construtos. 
Daiane Lindner Radons, Carla Rosane Da Costa Sccott, Vania De Fátima Barros Estivalete e Mauri Leodir Löbler

Tabela 4 - Unidimensionalidade e Validade Convergente

\begin{tabular}{|c|c|c|c|c|}
\hline & & Item & Erro & $t$-valor \\
\hline \multirow{19}{*}{$\begin{array}{l}\text { Índice de Prontidão Tecnológica } \\
\text { (TRI) }\end{array}$} & Otimismo & tri6 & & \\
\hline & & tri7 & 0,186 & 6,489 \\
\hline & & tri8 & 0,183 & 6,343 \\
\hline & & tri9 & 0,155 & 6,021 \\
\hline & Inovatividade & tri11 & & \\
\hline & & $\operatorname{tri13}$ & 0,160 & 5,461 \\
\hline & & tri14 & 0,198 & 6,733 \\
\hline & & $\operatorname{tri15}$ & 0,180 & 6,739 \\
\hline & & tri16 & 0,182 & 6,157 \\
\hline & & tri17 & 0,173 & 6,212 \\
\hline & Desconforto & tri24 & & \\
\hline & & $\operatorname{tri} 25$ & 0,166 & 5,503 \\
\hline & & tri26 & 0,163 & 5,989 \\
\hline & & tri27 & 0,168 & 5,239 \\
\hline & Insegurança & $\operatorname{tri28}$ & & \\
\hline & & tri29 & 0,089 & 10,853 \\
\hline & & tri30 & 0,078 & 9,601 \\
\hline & & tri31 & 0,084 & 9,360 \\
\hline & & tri36 & 0,077 & 8,047 \\
\hline \multirow{3}{*}{$\begin{array}{l}\text { Intenção de Continuidade de } \\
\text { Uso }\end{array}$} & Intenção de & IC1 & & \\
\hline & Continuidade de Uso & IC2 & 0,219 & 5,181 \\
\hline & & IC3 & 0,206 & 4,599 \\
\hline \multirow[t]{6}{*}{ Valores } & Mudança & V10 & & \\
\hline & & V26 & 0,118 & 6,785 \\
\hline & & V37 & 0,233 & 6,245 \\
\hline & Conservação & V16 & & \\
\hline & & V20 & 0,203 & 4,810 \\
\hline & & V25 & 0,248 & 4,507 \\
\hline
\end{tabular}

Fonte: Elaborada pelos autores

A última análise dos resultados compreende o teste das hipóteses (Tabela 6). As duas primeiras hipóteses possuíam o fator Mudança como fator antecedente e, os testes estatísticos comprovaram que os valores voltados a Mudança são antecedentes do Otimismo e da Inovatividade. A hipótese 1 foi significativa, $\operatorname{com} \beta=0,178$, comprovando que os valores que caracterizam a Mudança afetam positivamente o Otimismo com a tecnologia. A hipótese 2 também foi significativa, com $\beta=0,178$, indicando que os valores de Mudança impactam positivamente o caráter inovador dos respondentes.

A hipótese que se referia aos valores pessoais de Conservação como antecedentes do Desconforto foi rejeitada, demonstrando que os valores de tradição, conformidade e segurança não se associam à percepção de falta de controle sobre uma tecnologia, ou seja, a pessoa pode prezar por aspectos tradicionais e que denotam segurança e não se sentir oprimida por uma nova tecnologia. Já a quarta hipótese foi significativa, demonstrando a relação entre Conservação e Insegurança $(\beta=0,217$ e sign. $=0,000)$, ao passo que os valores pessoais voltados a Conservação afetam de forma positiva a Insegurança com a tecnologia. 
Compreendendo a influência dos valores pessoais na prontidão e na intenção de uso de tecnologias

Tabela 5 - Correlações entre os Constructos

\begin{tabular}{lcccccccccc}
\hline & $\boldsymbol{\mu}$ & $\boldsymbol{\Sigma}$ & OT & IN & DES & INS & IC & MUD & CON \\
\hline Otimismo (OT) & 3,69 & 0,73 & 1 & 0,057 & 0,002 & 0,000 & 0,067 & 0,009 & 0,003 \\
Inovatividade (IN) & 3,08 & 0,74 & $0,239^{* *}$ & 1 & 0,010 & 0,036 & 0,077 & 0,016 & 0,014 \\
Desconforto (DES) & 3,61 & 0,78 & 0,048 & $-0,102$ & 1 & 0,161 & 0,014 & 0,020 & 0,004 \\
Insegurança (INS) & 3,41 & 0,96 & $-0,002$ & $-0,191^{* *}$ & $0,402^{* *}$ & 1 & 0,030 & 0,003 & 0,034 \\
Continuidade (IC) & 4,16 & 0,67 & $0,259^{* *}$ & $0,278^{* *}$ & $-0,120$ & $-0,175^{* *}$ & 1 & 0,015 & 0,004 \\
Mudança (MUD) & 3,62 & 0,87 & 0,096 & $0,127^{*}$ & $0,143^{*}$ & $-0,059$ & 0,124 & 1 & 0,002 \\
Conservação (CON) & 2,97 & 0,93 & 0,062 & 0,121 & 0,069 & $0,186^{* *}$ & $-0,066$ & $-0,047$ & 1 \\
\hline
\end{tabular}

**. Correlações significantes ao nível de 0,01 (2-tailed).

*. Correlações significantes ao nível de 0,05 (2-tailed).

Fonte: Elaborada pelos autores

As seis hipóteses seguintes buscam verificar os antecedentes da Intenção de Continuidade de Uso. As hipóteses que associavam os fatores que são condutores da propensão ao uso de tecnologia à Intenção de Continuidade foram suportadas. Assim, a relação mais forte identificada foi entre Otimismo e Continuidade de Uso, com $\beta=0,257$ e sign. $=0,000$, demonstrando que quanto mais otimista for a pessoa, considerando a tecnologia, maior será sua intenção de continuar a utilizá-la, numa relação de dependência de $26,5 \%$.

Tabela 6 - Teste de Hipóteses

\begin{tabular}{llllllll}
\hline & & \multicolumn{2}{c}{ Relação } & Carga & Carga Pad. & P & Conclusão \\
H1 & Otimismo & $<---$ & Mudança & 0,187 & 0,178 & $0,005 * * *$ & Suportada \\
H2 & Inovatividade & $<---$ & Mudança & 0,220 & 0,178 & $0,005^{* * *}$ & Suportada \\
H3 & Desconforto & $<---$ & Conservação & 0,088 & 0,077 & 0,233 & Rejeitada \\
H4 & Insegurança & $<---$ & Conservação & 0,301 & 0,217 & $* * *$ & Suportada \\
H5 & Continuidade & $<---$ & Otimismo & 0,269 & 0,257 & $* * *$ & Suportada \\
H6 & Continuidade & $<---$ & Inovatividade & 0,149 & 0,167 & $0,006 * * *$ & Suportada \\
H7 & Continuidade & $<---$ & Desconforto & $-0,044$ & $-0,042$ & 0,487 & Rejeitada \\
H8 & Continuidade & $<---$ & Insegurança & $-0,078$ & $-0,089$ & 0,145 & Rejeitada \\
H9 & Continuidade & $<---$ & Mudança & 0,136 & 0,124 & $0,045 * *$ & Suportada \\
H10 & Continuidade & $<---$ & Conservação & $-0,053$ & $-0,044$ & 0,476 & Rejeitada \\
\hline
\end{tabular}

***. Correlações significantes ao nível de 0,01 (2-tailed).

**. Correlações significantes ao nível de 0,05 (2-tailed).

Fonte: Elaborada pelos autores

De forma semelhante, os indivíduos que apresentam caráter inovador, tendem a continuar a utilizar a tecnologia, conforme associação significativa positiva verificada entre Inovatividade e Continuidade, $\operatorname{com} \beta=0,167$ e sig. $=0,006$. Nesse contexto, Souza e Luce (2005) reforçam essa associação, concebendo que o Otimismo evidencia uma visão positiva da tecnologia e crenças, proporcionando conhecimento, flexibilidade e eficiência, nos quais, possibilitam maior Inovatividade. Ainda, Venkatesh et al. (2003) corroboram ao salientar que um usuário inovador possui uma tendência de ser pioneiro no uso da tecnologia, líder ou formador de opinião, o que consequentemente interliga a continuidade de uso da tecnologia de forma positiva. Nesse sentido, o Otimismo e a Inovatividade podem ser considerados com indutores na utilização da tecnologia, de forma que, segundo Keat e Mohan (2004), a Inovatividade possui relação significativa com a Intenção de Continuidade de Uso da tecnologia. 
As duas hipóteses seguintes ( $\mathrm{H7}$ e H8) foram rejeitadas. Dessa forma, os inibidores do uso da tecnologia não afetam o seu uso continuado, tendo em vista as associações não significativas entre Desconforto e Continuidade $(\beta=-0,042$ e sig. $=0,487)$; e, Insegurança e Continuidade $(\beta=-0,089$ e sig. $=0,145)$. Destaca-se que a associação, embora não significativa, foi negativa, conforme evidência da literatura de que os inibidores do uso de tecnologias tendem a evitar que o uso continue. Neste estudo, os fatores inibidores não exerceram influência na intenção de continuar a utilizar a tecnologia. No entanto, conforme a média das questões, demonstra-se que os respondentes apresentam preocupação com a Insegurança da tecnologia, assim como demonstram aspectos de Desconforto com seu uso, mas estes fatores não impactam negativamente o uso continuado.

Para Souza e Zakabi (2006), os fatores que impactam no uso continuado da tecnologia podem estar relacionados com a praticidade que a tecnologia oferece para as pessoas no seu dia a dia. Além disso, o mercado de trabalho exige habilidades cada vez mais intensas com o uso de tecnologias. Entretanto, as pessoas sentem-se inseguras com essa utilização, em função de diversas circunstâncias e fraudes que podem ocorrem, mas o cotidiano tem exigido a utilização de tecnologias, independentemente da percepção do indivíduo que, muitas vezes, pode ser negativa. Dessa forma, Silva (2010) contribui que a integração no trabalho com as tecnologias, como ferramentas, exige uma reflexão sistemática para utilização, pelo fato que as novas tecnologias proporcionam novas formas de ensino e aprendizagem, bem como novas competências exigidas pelo mercado e, assim, as pessoas tendem a se adaptar.

A nona hipótese que associava os valores de Abertura à Mudança ao fator Intenção de Continuidade de Uso foi suportada, $\operatorname{com} \beta=0,124$ e sign. 0,045 , indicando que os valores Hedonismo, Estimulação e Autodeterminação impactam positivamente a Intenção de um indivíduo em continuar utilizando determinada tecnologia.

Por fim, a relação entre valores pessoais da dimensão Conservação e Continuidade de Uso foi rejeitada, $\beta=-0,044$ e sign. 0,476 . Embora a associação não foi significativa, ela indicou uma relação negativa, de acordo com a proposição do estudo de que os valores pessoais voltados à Conservação poderiam afetar o uso continuado de tecnologia, já que pessoas que prezam pela Tradição, Conformidade e Segurança tendem a evitar o uso de tecnologias.

Destaca-se que os valores pessoais são preditivos relevantes da prontidão tecnológica, impactando nos fatores que conduzem e inibem o uso de tecnologias, afetando indiretamente o uso continuado de tecnologia. Dessa forma, evidencia-se que a Intenção de Uso é um fator complexo, que conta com variáveis que vão além dos valores pessoais e dos elementos inibidores. Por outro lado, o Otimismo e o caráter inovador dos indivíduos se mostraram impactantes na Intenção, indicando que aspectos positivos com o uso da tecnologia favorecem a utilização posterior.

Considerando o caráter dinâmico das tecnologias, o uso continuado parece que deixa de ser relevante sob o ponto de vista dos usuários. Novas tecnologias são implementadas em curto espaço de tempo e as pessoas não sabem se novos equipamentos e sistemas logo serão superados por versões ou alternativas mais recentes, que colocarão em xeque o uso de possibilidades anteriores. Isso se dá, em parte, pelo fato que as atuais políticas científicas e tecnológicas de incentivo à inovação propõem constantemente as inovações tecnológicas para a produção de conhecimento. De acordo com Neto (2006), elas baseiam-se no diagnóstico de mercado, na qual a capacidade de obter e usar conhecimento através do uso da tecnologia sejam aportes científicos, tecnológicos e apresentem inovação, podendo definir padrão de competição das trocas econômicas. Na Figura 4, são apresentados os resultados das hipóteses da pesquisa, sendo que seis hipóteses foram comprovadas ao nível de 
significância de $95 \%$ e quatro hipóteses não foram confirmadas, assim como os efeitos totais das variáveis e o coeficiente de determinação $\left(R^{2}\right)$ da Intenção de Continuidade de Uso.

Figura 4 - Resultados das Hipóteses do Estudo e Efeitos Totais

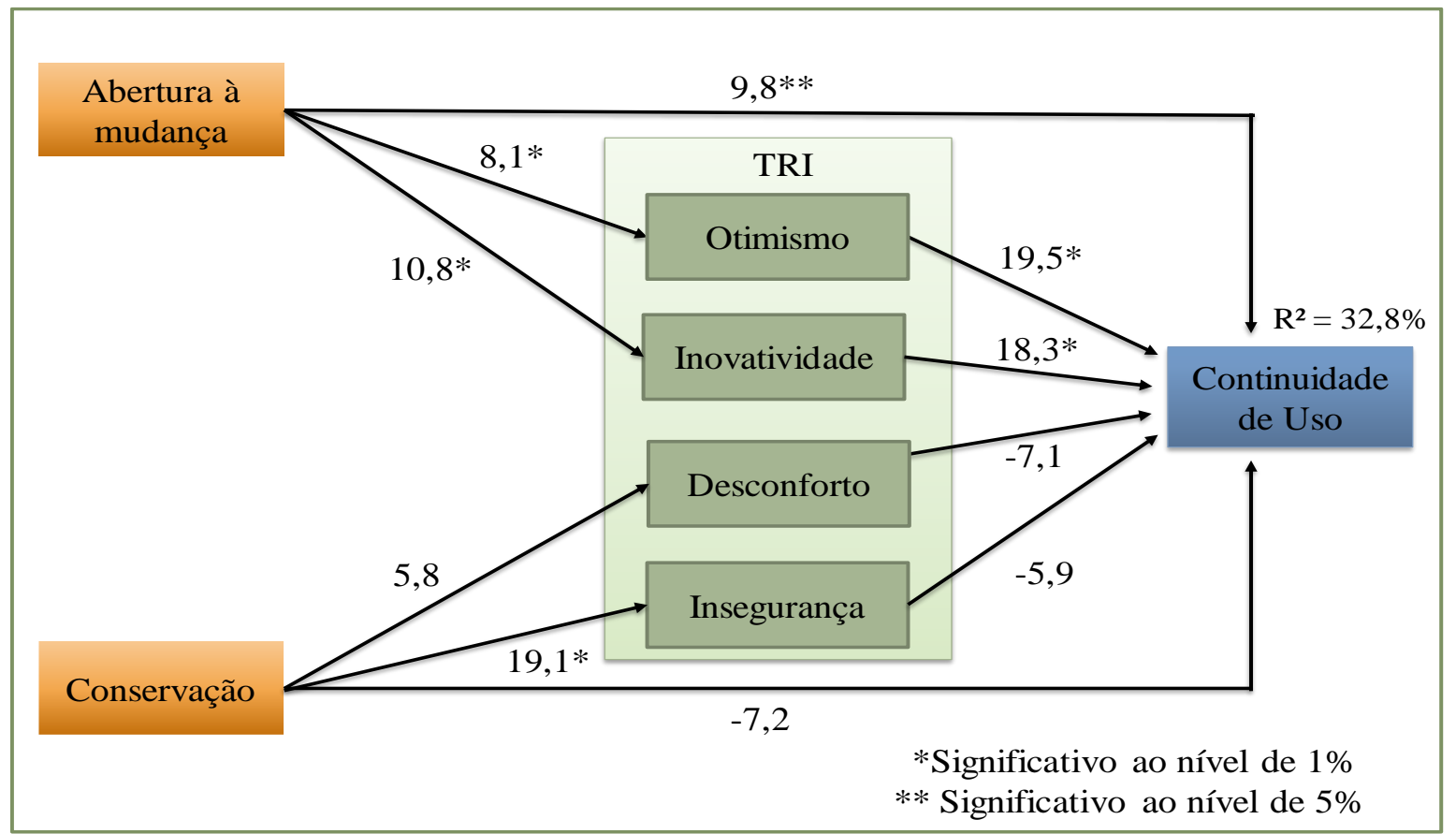

Fonte: Elaborada pelos autores

O coeficiente de determinação $\left(R^{2}\right)$ da Continuidade apresentou o valor de $32,8 \%$ e, conforme Cohen (1988), indica um valor significativo dos fatores componentes do modelo como antecedentes que explicam a Continuidade de Uso. Destaca-se que o maior efeito total na Intenção de Continuidade é do fator Otimismo $(19,5)$, seguido da Inovatividade $(18,3)$, corroborando os resultados da Tabela 6 . Outro efeito expressivo detectado é dos valores da Conservação na Insegurança $(19,1)$.

Dessa forma, das dez hipóteses propostas, seis delas foram confirmadas, mostrando que a Continuidade de uso é influenciada, e de forma positiva, pelo Otimismo, Inovatividade e Abertura à Mudança. Também foi comprovado que os valores pessoais de Abertura à Mudança e Conservação impactam positivamente os condutores de propensão ao uso de tecnologias, Otimismo e Inovatividade, assim como um dos inibidores, a Insegurança.

\section{CONSIDERAÇÕES FINAIS}

O estudo teve por objetivo principal verificar a influência dos valores pessoais na prontidão tecnológica e na Intenção de Continuidade de Uso das tecnologias pelos jovens. Para tanto, foram propostas dez hipóteses e, a partir das análises estatísticas realizadas, foram suportadas seis relações.

As quatro hipóteses rejeitadas indicam que os fatores inibidores da prontidão tecnológica (Desconforto e Insegurança) e os valores pessoais de Conservação não influenciam a Continuidade de Uso, além dos valores de Conservação não impactar o Desconforto. Dessa forma, a Continuidade de Uso é influenciada, e de forma positiva, pelo Otimismo, Inovatividade e valores de Abertura à Mudança. As hipóteses confirmadas indicam ainda que os valores pessoais de Abertura à Mudança e Conservação impactam positivamente os condutores de propensão ao uso de tecnologias, Otimismo e Inovatividade, e um dos 
inibidores, a Insegurança. Dessa forma, demonstra-se que os valores pessoais são fatores relevantes para a propensão de uso de tecnologias, ou seja, os princípios ou crenças sobre comportamentos ou estados de existência que são importantes para o indivíduo vão determinar sua inclinação, positiva ou negativa, em relação às tecnologias.

Em relação ao modelo proposto, os resultados obtidos comprovaram a validade do modelo global (união dos Valores Pessoais voltados a Abertura à Mudança e Conservação, Índice de Prontidão Tecnológica e Modelo de Pós Aceitação de Tecnologia). As análises realizadas indicaram que o modelo apresenta bons índices de ajustes, unidimesionalidade, validade convergente e validade discriminante. $O$ cálculo do alpha de Cronbach indicou que os constructos possuem confiabilidade.

Destaca-se que os valores da dimensão Abertura à Mudança são relevantes na propensão à novas tecnologias e na Intenção de Continuidade de Uso das mesmas pelos jovens, os quais são considerados mais abertos a novas TICs e um dos primeiros segmentos de consumidores a adotar compras móveis (SAN-MARTÍN; PRODANOVA; JIMÉNEZ, 2015). Não obstante, Pinese, Moriguchi e Pimenta (2015) identificaram três perfis de jovens consumidores no mercado de ações, sendo um deles orientado por valores de Abertura à Mudança e que possui como característica a busca da liberdade e independência visando uma vida excitante e cheia de aventura. Nesse sentido, os jovens prezam por inovação e mudanças, se distanciando de uma perspectiva mais conservadora de valores, que é marcada por evitar a instabilidade e as incertezas (MARBACH et al., 2019).

Quanto às implicações teóricas, este estudo inova ao testar empiricamente relações entre a propensão de uso de tecnologias e os valores pessoais, associações que não foram investigadas anteriormente, conforme busca realizada na base de dados Web of Science. Assim, contribuições na literatura são destacadas ao avançar na compreensão das características individuais que orientam as ações das pessoas, especialmente, voltadas a prontidão e ao uso continuado de tecnologias. Ainda que os valores pessoais não podem ser alterados, observa-se que os valores Autodeterminação, Estimulação e Hedonismo são relevantes para a propensão e o uso continuado de tecnologias pelos jovens. Reitere-se que estudos voltados a adoção e a utilização de novas tecnologias precisam considerar que cada geração tende a apresentar um comportamento específico, prezando por valores diferentes das gerações anteriores, o que implica em investigar diferentes perfis de usuários.

As implicações práticas se referem as particularidades de uso de tecnologias conforme os valores pessoais de cada indivíduo e considerando a geração a que pertence. Assinala-se, uma tendência dos jovens de não permanecerem vinculados à uma determinada tecnologia, mas buscarem novas opções, o que implica em estratégias organizacionais que prezem por prazer, entusiasmo, novidade, criatividade, pensamento independente e desafio na vida. Além disso, as pessoas da geração Z, nascidas entre 1991 e 2000, estão ingressando no mercado de trabalho e as organizações precisam reconhecer as diferenças individuais no sentido de criar um ambiente hospitaleiro para uma força de trabalho diversificada (JARRAHI; ESHRAGHI, 2019).

O estudo apresenta limitações referentes à amostra ser formada apenas por estudantes, do Ensino Superior e do Ensino Técnico, e carência de estudos sobre valores pessoais e tecnologias. Além disso, embora que o Questionário de Perfis de Valores já tenha sido utilizado no contexto nacional, observa-se a limitação de trabalhos com foco em sua melhoria e que combinem os construtos da escala com outros fatores, de diferentes modelos. Neste sentido, sugerem-se novos estudos sobre as relações entre valores pessoais e prontidão 
tecnológica, assim como o acréscimo de construtos que possam auxiliar na explicação da adoção e uso de tecnologias.

\section{REFERÊNCIAS}

BALANCIERI, R. et al. A análise de redes de colaboração científica sob as novas tecnologias de informação e comunicação: um estudo na Plataforma Lattes. Ciência da Informação, Brasília, v. 34 , n. 1, p. $64-77,2005$. DOI: 10.1590/S0100-19652005000100008.

BHATTACHERJEE, A. Understanding information systems continuance: an expectation confirmation model. MIS Quarterly, Minneapolis, v. 25, n. 3, p. 351-70, 2001. DOI: $10.2307 / 3250921$.

BIJMOLT, T. H. A.; HUIZINGH, E. K. R. E.; KRAWCZYK, A. Effects of complaint behaviour and service recovery satisfaction on consumer intentions to repurchase on the internet. Internet Research, Melbourne, v. 24, n. 5, p. 608-628, 2014. DOI: 10.1108/IntR-03-2012-0056.

BOYLE, E. A study of entrepreneurial brand building in the manufacturing sector in the UK. Journal of Product \& Brand Management, Melbourne, v. 12, n. 2, p. 79-93, 2003. DOI: 10.1108/10610420310469779.

CHEN, S. C.; CHEN, H. H.; CHEN, M. F. Determinants of satisfaction and continuance intention towards self-service technologies. Industrial Management \& Data Systems, Melbourne, v. 109, n. 9, p. 1248-1263, 2009. DOI: 10.1108/02635570911002306.

COHEN, J. Statistical power analysis for the behaviors science. 2 ed. New Jersey: Laurence Erlbaum Associates, Publishers, Hillsdale, 1988.

CROSSAN, M. M.; APAYDIN, M. A multi-dimensional framework of organizational innovation: a systematic review of the literature. Journal of Management Studies, Durham, v. 47, n. 6, p. 1154-1191, 2010. DOI: 10.1111/j.1467-6486.2009.00880.x.

DAGHFOUS, N.; PETROF, J. V.; PONS, F. Values and adoptions of innovations: a cross-cultural study. Journal of Consumer Marketing, Melbourne, v. 16, p. 314-331, 1999. DOI: 10.1108/07363769910277102.

FALSARELLA, O. M.; JANNUZZI, C. A. S. C. Planejamento Estratégico Empresarial e Planejamento de Tecnologia de Informação e Comunicação: uma abordagem utilizando projetos. Revista Scielo Gest. Prod., São Carlos, v. 24, n. 3, p. 610-621, 2017. DOI: 10.1590/0104-530x481-16.

FREED, L.; ANDERSON, J. Holiday satisfaction with online shopping stagnates. ForSee, Ann Arbor, MI. Disponível em: <www.waafiles.org/whitepapers/online-retail-satisfaction-indexu.s.-holiday-2012-foresee.pdf>. Acesso em: 15 jun. 2018. 
GASTALDELLO, A. T. A Influência de Valores Pessoais de Executivos Brasileiros e Argentinos em Negociações Comerciais. 1999. 152 p. Dissertação (Mestrado em Administração) Universidade Federal do Rio Grande do Sul, Porto Alegre, 1999.

GHESTI, G. F. et al. Desenvolvimento tecnológico e a maturidade das pesquisas no âmbito das instituições de pesquisa científica e tecnológica (ICT) no Brasil. Cadernos de Prospecção, Salvador, v. 12, n. 1, p. 31-47, 2019. DOI: 10.9771/cp.v12n1p31.

GIRALDI, J. M. E. A influência dos valores pessoais dos consumidores no país de origem: um estudo com eletrodomésticos chineses. 2006. 226 p. Tese (Doutorado em Administração) Universidade de São Paulo, São Paulo, 2006.

GROHMANN, M. Z. et al. Compreensão da satisfação e intenção de continuidade de uso da tecnologia por meio do Índice de Prontidão Tecnológica. Revista de Administração e Inovação, São Paulo, v. 11, n. 3, p. 101-124, 2014.

HAIR JR. J. F.; et al. Análise Multivariada de Dados. 6 ed. Porto Alegre: Bookman, 2009.

HERRANDO, C., JIMENEZ-MARTINEZ, J.; MARTIN-DE HOYOS, M. J. Tell me your age and I tell you what you trust: the moderating effect of generations. Internet Research, Enschede, v. 29, n. 4, p. 799-817, 2019. DOI: 10.1108 / IntR-03-2017-0135.

HOFSTEDE, G. Culture and Organizations: software of the mind. New York: McGraw-Hill, 1997.

ISOMURSU, M. et al. Understanding Human Values in adopting new technology - A case study and methodological discussion. International. International Journal of Human-Computer Studies, v. 69, n. 1, p. 183-200, 2011. DOI: 10.1016 / j.ijhcs.2010.12.001.

JARRAHI, M. H.; ESHRAGHI, A. Digital natives vs digital immigrants: A multidimensional view on interaction with social technologies in organizations. Journal of Enterprise Information Management, Londres, v. 32, n. 6, p. 1051-1070, 2019. DOI: 10.1108/JEIM-04-2018-0071.

KAMAKURA, W. A.; NOVAK, T. P. Value-system segmentation: exploring the meaning of LOV. Journal of Consumer Research, Oxford, v. 19, n. 1, p. 119-132, 1992.

KEAT, K. T.; MOHAN, A. Integration of TAM based electronic commerce models for trust. Journal of American Academy of Business, Washington, v. 5, p. 404 - 410, 2004.

KIM, C.; et al. Factors influencing Internet shopping value and customer repurchase intention. Electronic Commerce Research and Applications, Amsterdam, v. 11, n. 4, p. 374-387, 2012. DOI: 10.1016/j.elerap.2012.04.002.

LAUDON, K. C.; LAUDON, J. P. Sistemas de informação gerenciais. São Paulo: Prentice Hall, 2004. 
LEAO, A. L. M. S.; SOUZA NETO, A. F.; MELLO, S. C. B. Compreendendo os valores das marcas: aplicação da lista de valores em diferentes indústrias. Rev. adm. contemp., Maringá, v. 11, n. 2, p. 27 - 48, 2007. DOI: 10.1590/S1415-65552007000200003.

LENARTOWICZ, T.; JOHNSON, J. P. A cross-national assessment of the values of Latin America managers: contrasting hues or shades of gray? Journal of International Business Studies, Washington, v. 34, n. 3, p. 266 - 280, 2003. DOI: 10.1057/palgrave.jibs.8400032.

MACLENNAN, M. L. F. et al. Associação entre intensidade de uso de mídias sociais, credibilidade e decisão de compra. Navus: Revista de Gestão e Tecnologia, Florianópolis, v. 4, n. 2, p. 65-77, 2014. DOI: 10.22279/navus.2014.v4n2.p65-77.192.

MALHOTRA, N. Pesquisa de marketing: uma orientação aplicada. Porto Alegre: Bookman, 2011.

MARBACH, J. et al. Consumer engagement in online brand communities: the moderating role of personal values. European Journal of Marketing, Bingley, v. 53, n. 9, p. 1671-1700, 2019. DOI: 10.1108/EJM-10-2017-0721.

MICK, D. G.; FOURNIER, S. Paradoxes of Technology: Consumer Cognizance, Emotions and Coping Strategies. Journal of Consumer Research, Oxford, v. 25, p. 123-143, 1998. DOI: $10.1086 / 209531$.

MUKERJEE, H. S.; DESHMUKH, G. K.; PRASAD, U. D. Technology Readiness and Likelihood to Use Self-Checkout Services Using Smartphone in Retail Grocery Stores: Empirical Evidences from Hyderabad, India. Business Perspectives and Research, Thousand Oaks, v. 7, p. 1-15, 2018. DOI: $10.1177 / 2278533718800118$.

NETO, I. Tecnologia, Educação e Trabalho. Revista Tecnologia e Sociedade, Curitiba, n. 2, 2006. DOI: $10.3895 /$ rts.v2n2.2465.

PARASURAMAN, A. Technology readiness index (TRI): a multiple-item scale to mensure readiness to embrace new technologies. Journal of Service Research, College Park, v. 2, p. 307- 320, 2000. DOI: 10.1177/109467050024001.

PARASURAMAN, A.; COLBY, C. L. Marketing para produtos inovadores: como e por que seus clientes adotam tecnologia. Porto Alegre: Bookman, 2002.

PASSERINO, L. M.; PASQUALOTTI, P. R. A inclusão digital como prática social: uma visão sóciohistórica da apropriação tecnológica em idosos. In: PORTELLA, M. R.; PASQUALOTTI, A.; GAGLIETTI, M. (Orgs.). Envelhecimento humano: saberes e fazeres. Passo Fundo: UPF, 2006. p. 246-260.

PEREIRA, R. E. An adopter-centered approach to understanding adoption of innovations. European Journal of Innovation Management, Bingley, v. 5, n. 1, p. 40-49, 2002. DOI: 10.1108/14601060210415162. 
PESTANA, M.; GAGEIRO, J. Análise de dados para ciências sociais. Lisboa: Edições Silabo, 2000.

PINESE, H. P.; MORIGUCH, S. N.; PIMENTA, M. P. Os valores pessoais que orientam o comportamento de jovens universitários como investidores da bolsa. Revista de Administração da Universidade Federal de Santa Maria, Santa Maria, v. 8, n. 4, p. 598-615, 2015. DOI: 10.5902/19834659111110483.

RAMÍREZ-CORREA, P.; GRANDÓN, E. E.; RONDÁN-CATALUÑA, J. Users segmentation based on the Technological Readiness Adoption Index in emerging countries: The case of Chile. Technological Forecasting and Social Change, Amsterdam, v. 155, 2020. DOI: 10.1016/j.techfore.2020.120035.

ROCCAS, S.; SCHWARTZ, S. H; AMIT, A. Personal value priorities and national identification. Political Psychology, Malden, v. 31, n. 3, p. 393-419, 2010. DOI: 10.1111/j.14679221.2010.00763.x.

ROKEACH, M. The nature of human values. New York: The Free Press, 1973.

SAN-MARTÍN, S.; PRODANOVA, J.; JIMÉNEZ, N. The impact of age in the generation of satisfaction and WOM in mobile shopping. Journal of Retailing and Consumer Services, London, v. 23, p. 1-8, 2015. DOI: 10.1016/j.jretconser.2014.11.001.

SCHIFFMAN, L. G.; SHERMAN, E.; LONG, M. M. Toward a better understanding of the interplay of personal values and the Internet. Psychology \& Marketing, London, v. 20, n. 2, p. 169-186, 2003. DOI: 10.1002/mar.10066.

SCHWARTZ, S. H. Universals in the content and structure of values: theoretical advances and empirical tests in 20 countries. In: ZANNA, M. (Org.). Advances in experimental social psychology. Orlando, FL: Academic, v. 25, p. 1-65, 1992.

SCHWARTZ, S. H. Validade e aplicabilidade da teoria de valores. In: A. TAMAYO; J. B. PORTO (Eds.), Valores e comportamento nas organizações (p. 56-95). Petrópolis: Vozes, 2005.

SCHWARTZ, S. H.; BILSKY, W. Toward a universal structure of human values. Journal of Personality and Social Psychology, Washington, v. 53, n. 3, p. 550-562, 1987. DOI: 10.1037 / 0022-3514.53.3.550.

SCHWARTZ, S. H. et al. Extending the cross-cultural validity of the theory of basic human values with a different method of measurement. Journal of Cross Cultural Psychology, Thousand Oaks, v. 32, p. 519-542, 2001. DOI: 10.1177/0022022101032005001.

SIMÕES, R.; GIRALDI, J.; OLIVEIRA, S. Influência de valores pessoais no comportamento "verde" do consumidor. Rev. Portuguesa e Brasileira de Gestão, Rio de Janeiro, v. 11, n. 4, p. 26-37, 2012. 
SILVA, J. D. Tecnologia e educação: artefatos tecnológicos na dependência de mediadores transformadores. APASE, São Paulo, Ano XI, n. 26, p. 7-10, 2010.

SOUZA, R. V.; LUCE, F. B. Adoção de produtos e serviços baseados em tecnologia: uma avaliação da aplicabilidade do Technology Readiness Index (TRI) no Brasil. In: ENCONTRO NACIONAL DA ANPAD, 27., 2003, Atibaia. Anais... Atibaia: ANPAD, 2003.

SOUZA, R. V.; LUCE, F. B. Avaliação da aplicabilidade do Technology Readiness Index (TRI) para a adoção de produtos e serviços baseados em tecnologia. Revista de Administração Contemporânea, Curitiba, v. 9, n. 3, 2005. DOI: 10.1590/S1415-65552005000300007.

SOUZA, O.; ZAKABI. R. Imersos na Tecnologia e mais espertos. Revista Veja, São Paulo, n. 1938, p. 66-75, 2006.

TEIXEIRA, M. L. M.; MONTEIRO, R. S. Valores Pessoais no ambiente de negócios. Em Teixeira, M. L. M. (Org). Valores Humanos e Gestão: novas perspectivas. São Paulo: Editora Senac, 2008.

TRIVIÑOS, A. N. S. Introdução à pesquisa em ciências sociais: a pesquisa qualitativa em educação. São Paulo: Atlas, 2007. 175 p.

VAZ, C. A. Google marketing: o guia definitivo de marketing digital. 2. ed. São Paulo: Novatec, 2008.

VENKATESH, V.; MORRIS, M. G.; DAVIS, G. B.; DAVIS, F. D. User acceptance of information technology: toward a unified view. MIS Quarterly, Minneapolis, v. 27, p. 425-478, 2003. DOI: $10.2307 / 30036540$.

VERAS, M. Gestão da tecnologia da informação: Sustentação e inovação para a transformação digital. Rio de Janeiro: Brasport, 2019.

VON BORELL, D. A.; CAMBIELD, C. E. R.; RODRIGUES, R. G. Uma análise da relação entre valores pessoais e satisfação com o trabalho. Revista de Administração da Universidade Federal de Santa Maria, Santa Maria, v. 11, n. 5, p. 1240-1256, 2019. DOI: 10.5902/1983465916992.

WANG, G.; DOU, W.; ZHOU, N. Consumption attitudes and adoption of new consumer products: a contingency approach. European Journal of Marketing, Bingley, v. 42, n. 1/2, p. 238 - 254, 2008. DOI: 10.1108 / 03090560810840998. 
Daiane Lindner Radons, Carla Rosane Da Costa Sccott, Vania De Fátima Barros Estivalete e Mauri Leodir Löbler

\section{Apêndice $A$ - Instrumento de coleta de dados utilizado na pesquisa}

\section{I - Escala TRI e Intenção de Continuidade de Uso}

\begin{tabular}{|c|c|}
\hline tri1 & A tecnologia permite que as pessoas tenham mais controle sobre o seu dia-a-dia. \\
\hline tri2 & Produtos e serviços que utilizam as mais novas tecnologias são muito mais convenientes de usar. \\
\hline tri3 & Eu gosto da ideia de fazer negócios pelo computador porque não fico restrito ao horário comercial. \\
\hline tri4 & Eu prefiro usar a tecnologia mais avançada disponível. \\
\hline tri5 & $\begin{array}{l}\text { Eu gosto de programas de computador que me permitam adequar as coisas às suas próprias } \\
\text { necessidades. }\end{array}$ \\
\hline tri6 & A tecnologia faz com que eu fique mais eficiente no seu trabalho/estudo. \\
\hline tri7 & Eu considero as novas tecnologias mentalmente estimulantes. \\
\hline tri8 & A tecnologia me dá mais liberdade de movimento. \\
\hline tri9 & Aprender sobre tecnologia pode ser tão recompensador quanto a própria tecnologia. \\
\hline tri10 & Eu estou seguro de que as máquinas seguirão as minhas instruções. \\
\hline tri11 & Outras pessoas me pedem conselhos sobre novas tecnologias. \\
\hline tri12 & Parece que meus amigos estão aprendendo sobre as mais novas tecnologias mais do que eu. \\
\hline tri13 & $\begin{array}{l}\text { Em geral, eu estou entre os primeiros do meu grupo de amigos a adquirir uma nova tecnologia logo } \\
\text { que ela surge. }\end{array}$ \\
\hline tri14 & $\begin{array}{l}\text { Normalmente, eu consigo entender os novos produtos e serviços de alta tecnologia sem a ajuda de } \\
\text { outros. }\end{array}$ \\
\hline tri15 & Eu estou atualizado com os últimos desenvolvimentos tecnológicos das suas áreas de interesse. \\
\hline tri16 & Eu gosto do desafio de entender equipamentos de alta tecnologia. \\
\hline tri17 & Eu tenho menos problemas que outras pessoas para fazer a tecnologia trabalhar a meu favor. \\
\hline tri18 & $\begin{array}{l}\text { Os serviços de suporte técnico (por telefone ou internet) não ajudam, porque não explicam as } \\
\text { coisas em termos compreensíveis. }\end{array}$ \\
\hline tri19 & $\begin{array}{l}\text { Às vezes, eu acho que os sistemas de tecnologia não são projetados para serem usados por pessoas } \\
\text { comuns. }\end{array}$ \\
\hline tri20 & $\begin{array}{l}\text { Não existe manual de produto ou serviço de alta tecnologia que seja escrito em uma linguagem } \\
\text { simples. }\end{array}$ \\
\hline tri21 & $\begin{array}{l}\text { Quando eu utilizo o suporte técnico de um fornecedor de produtos ou serviços de alta tecnologia, } \\
\text { às vezes, me sinto como se alguém, que sabe mais do que eu, estivesse tirando vantagem da } \\
\text { situação. }\end{array}$ \\
\hline tri22 & $\begin{array}{l}\text { Na compra de um produto ou serviço de alta tecnologia, eu prefiro o modelo básico em vez de um } \\
\text { modelo com muitas características adicionais. }\end{array}$ \\
\hline tri23 & $\begin{array}{l}\text { É constrangedor quando eu tenho problemas com algum equipamento de alta tecnologia enquanto } \\
\text { outras pessoas estão olhando. }\end{array}$ \\
\hline tri24 & $\begin{array}{l}\text { Deveria haver cuidado ao substituir tarefas desempenhadas por pessoas pela tecnologia, pois novas } \\
\text { tecnologias podem falhar. }\end{array}$ \\
\hline tri25 & $\begin{array}{l}\text { Muitas das novas tecnologias apresentam riscos à saúde ou à segurança que não são descobertos } \\
\text { até que as pessoas tenham utilizado a tecnologia. }\end{array}$ \\
\hline tri26 & Novas tecnologias tornam muito fácil para o governo e as empresas espionar as pessoas. \\
\hline tri27 & As tecnologias parecem sempre falhar no pior momento possível. \\
\hline tri28 & Eu não considero seguro fornecer o número do seu cartão de crédito pelo computador. \\
\hline tri29 & Eu não considero seguro fazer qualquer tipo de transação financeira pela Internet. \\
\hline tri30 & Eu tenho receio de que as informações que envio pela internet serão vistas por outras pessoas. \\
\hline tri31 & $\begin{array}{l}\text { Eu não me sinto seguro em fazer negócios com uma empresa que só pode ser acessada pela } \\
\text { internet. }\end{array}$ \\
\hline tri32 & $\begin{array}{l}\text { Qualquer transação realizada eletronicamente deveria ser confirmada, posteriormente, por algo } \\
\text { escrito. }\end{array}$ \\
\hline tri33 & $\begin{array}{l}\text { Sempre que algo se torna automatizado, é necessário checar, cuidadosamente, se a máquina ou o } \\
\text { computador não está cometendo erros. }\end{array}$ \\
\hline tri34 & O contato humano é muito importante quando se faz negócios com uma empresa. \\
\hline tri35 & Quando eu ligo para uma empresa, prefiro falar com uma pessoa do que com uma máquina. \\
\hline tri36 & $\begin{array}{l}\text { Quando eu forneço informação a uma máquina ou pela internet, nunca posso ter certeza de que } \\
\text { ela, realmente, chegou ao destino certo. }\end{array}$ \\
\hline
\end{tabular}


Compreendendo a influência dos valores pessoais na prontidão e na intenção de uso de tecnologias

\begin{tabular}{|l|l|}
\hline IC1 & Eu pretendo continuar usando a tecnologia mais do que desistir do uso. \\
\hline IC2 & Minhas intenções são de continuar usando a tecnologia do que usar meios alternativos/físicos. \\
\hline IC3 & Se eu pudesse, eu gostaria de desistir de usar tecnologia. \\
\hline
\end{tabular}

\section{II - Escala de Valores}

\begin{tabular}{|c|c|}
\hline Valor & Escala de Valores \\
\hline \multirow[t]{4}{*}{ Autodeterminação } & $\begin{array}{l}1 \text { - Pensar em novas ideias e ser criativa é importante para ela. Ela gosta de fazes coisas } \\
\text { de maneira própria e original. }\end{array}$ \\
\hline & $\begin{array}{l}\text { 11- É importante que ela toma suas próprias decisões sobre o que faz. Ela gosta de ser } \\
\text { livre para planejar e escolher suas atividades. }\end{array}$ \\
\hline & $\begin{array}{l}22 \text { - Ela acha que é importante demonstrar interesse pelas coisas. Ela gosta de ser } \\
\text { curiosa e tentar entender todos os tipos de coisas. }\end{array}$ \\
\hline & 34 - É importante para ela ser independente. Ela gostar de contar com si própria. \\
\hline \multirow[t]{3}{*}{ Estimulação } & $\begin{array}{l}6 \text { - Ela acha que é importante fazer várias coisas diferentes na vida. Ela sempre procura } \\
\text { novas coisas para experimentar. }\end{array}$ \\
\hline & 15 - Ela gosta de se arriscar. Ela está sempre procurando aventuras. \\
\hline & 30 - Ela gosta de surpresas. É importante para ela ter uma vida emocionante. \\
\hline \multirow[t]{3}{*}{ Hedonismo } & $\begin{array}{l}10 \text { - Ela procura todas as oportunidades para se divertir. É importante para ela fazer } \\
\text { coisas que lhe dão prazer. }\end{array}$ \\
\hline & 26 - Aproveitar os prazeres da vida é importante para ela. Ela gosta de se mimar. \\
\hline & 37 - Ela realmente quer aproveitar a vida. Se divertir é muito importante para ela. \\
\hline \multirow[t]{5}{*}{ Segurança } & $\begin{array}{l}5 \text { - É importante para ela viver em um ambiente seguro. Ela evita qualquer coisa que } \\
\text { possa colocar sua segurança em perigo. }\end{array}$ \\
\hline & $\begin{array}{l}\text { 14-A segurança de seu país é muito importante para ela. Ela acha que o governo deve } \\
\text { estar atento a ameaças de origem interna ou externa. }\end{array}$ \\
\hline & $\begin{array}{l}21 \text { - É importante para ela que as coisas estejam organizadas e limpas. Ela realmente } \\
\text { não gosta que as coisas estejam bagunçadas. }\end{array}$ \\
\hline & 31 - Ela se esforça para não ficar doente. Estar saudável é muito importante para ela. \\
\hline & $\begin{array}{l}35 \text { - Contar com um governo estável é importante para ela. Ela se preocupa com a } \\
\text { preservação da ordem social. }\end{array}$ \\
\hline \multirow[t]{4}{*}{ Conformidade } & $\begin{array}{l}\text { 7- Ela acredita que as pessoas deveriam fazer o que lhes é ordenado. Ela acredita que } \\
\text { as pessoas deveriam sempre seguir as regras, mesmo quando ninguém está } \\
\text { observando. }\end{array}$ \\
\hline & $\begin{array}{l}16 \text { - É importante para ela se comportar sempre adequadamente. Ela quer evitar fazer } \\
\text { qualquer coisa que as pessoas possam achar errado. }\end{array}$ \\
\hline & $\begin{array}{l}28 \text { - Ela acredita que deve sempre respeitar seus pais e os mais velhos. É importante } \\
\text { para ela ser obediente. }\end{array}$ \\
\hline & $\begin{array}{l}36 \text { - É importante para ela ser sempre educada com os outros. Ela tenta nunca } \\
\text { incomodar ou irritar os outros. }\end{array}$ \\
\hline \multirow[t]{4}{*}{ Tradição } & $\begin{array}{l}9 \text { - Acha que é importante não querer mais do que se tem. Ela acredita que as pessoas } \\
\text { deveriam estar satisfeitas com o que têm. }\end{array}$ \\
\hline & $\begin{array}{l}20 \text { - Ser religiosa é importante para ela. Ela se esforça para seguir suas crenças } \\
\text { religiosas. }\end{array}$ \\
\hline & $\begin{array}{l}25 \text { - Ela acha que é melhor fazer as coisas de maneira tradicional. É importante para } \\
\text { ela manter os costumes que aprendeu. }\end{array}$ \\
\hline & $\begin{array}{l}38 \text { - É importante para ela ser humilde e modesta. Ela tenta não chamar atenção para } \\
\text { si. }\end{array}$ \\
\hline
\end{tabular}

